\title{
Establishing control of stereotypy by an antecedent stimulus using punishment
}

\author{
Shannon S. Haag \\ West Virginia University
}

Follow this and additional works at: https://researchrepository.wvu.edu/etd

\section{Recommended Citation}

Haag, Shannon S., "Establishing control of stereotypy by an antecedent stimulus using punishment" (2004). Graduate Theses, Dissertations, and Problem Reports. 2072.

https://researchrepository.wvu.edu/etd/2072

This Dissertation is protected by copyright and/or related rights. It has been brought to you by the The Research Repository @ WVU with permission from the rights-holder(s). You are free to use this Dissertation in any way that is permitted by the copyright and related rights legislation that applies to your use. For other uses you must obtain permission from the rights-holder(s) directly, unless additional rights are indicated by a Creative Commons license in the record and/ or on the work itself. This Dissertation has been accepted for inclusion in WVU Graduate Theses, Dissertations, and Problem Reports collection by an authorized administrator of The Research Repository @ WVU.

For more information, please contact researchrepository@mail.wvu.edu. 


\title{
Establishing control of stereotypy
}

by an antecedent stimulus using punishment

\section{Shannon S. Haag}

\author{
Dissertation Submitted to the Eberly College of Arts and Sciences \\ at West Virginia University \\ in Partial Fulfillment of the Requirements \\ for the Degree of
}

\author{
Doctor of Philosophy \\ in \\ Psychology
}

\author{
Cynthia M. Anderson, Ph.D., Committee Chair \\ Jennifer A. Margrett, Ph.D. \\ B. Kent Parker, Ph.D. \\ Michael Perone, Ph.D \\ Dean C. Williams, Ph.D.
}

Department of Psychology

Morgantown, West Virginia

2004

Keywords: stimulus control, punishment, stereotypy, self-stimulatory responding, manding, developmental disabilities

Copyright 2004 Shannon S. Haag 


\author{
Abstract \\ Establishing control of stereotypy \\ by an antecedent stimulus using punishment \\ Shannon S. Haag
}

Few studies have demonstrated conclusively that the use of punishment in the presence of an antecedent, previously arbitrary stimulus can bring responding under control of that stimulus. The first purpose of this study was to determine if a stimulus, because of a differential history of punishment, would come to function as a signal (i.e., discriminative stimulus) for whether unusual repetitive behavior (i.e., stereotypy) would be punished or unpunished and, as such, control the occurrence of stereotypy. The second purpose, then, was to determine whether participants would request the stimulus correlated with nonpunishment. Three adults with mental retardation participated. Initially, analyses were conducted to develop hypotheses about the effects of environmental variables on participants' repetitive behaviors. Results of these analyses suggested that the responding of all participants likely was sensory maintained. The purpose of Experiment 1 was to determine whether responding could be brought under stimulus control using punishment. Obtained results suggest that stimulus control was achieved with all participants, and that the stimulus correlated with nonpunishment, and not the punisher itself, served as a discriminative stimulus for the occurrence of stereotypy. The purpose of Experiment 2 was to determine whether participants would acquire a response (i.e., a mand) maintained by access to the stimulus conditions correlated with nonpunishment, and if a practical intervention for stereotypy then could be developed. Results suggest that for two of three participants, such a mand was acquired and for all participants, and practical interventions using stimulus control and mand training were developed. Overall, results obtained in this study contribute to the literature by demonstrating that it is possible to obtain stimulus control using punishment while determining conclusively which stimulus served as the discriminative stimulus. The results have implications for the development of antecedent interventions for stereotypy, as it may be possible to control responding such that it occurs only in situations where it is more appropriate (e.g., when the individual is alone). Thus, stereotypy can be controlled in a manner that benefits the individual, but does not require frequent punishment or complete suppression of an apparently reinforcing behavior. 


\section{Acknowledgments}

Many, many individuals contributed to this dissertation who deserve thanks for its completion. First, I would like to thank the participants and their guardians, who made the dissertation possible. For their support of this and other research, I also thank Denise Gray, Angela Roy, the direct-care staff at the cottages, the vocational staff at Dog Biscuits, the administration at the Parsons State Hospital and Training Center, and the staff of the Parsons Research Center of the University of Kansas. I would like to thank Adam Doughty and Colleen Eisenbart for assistance in conducting sessions and I am very grateful to Carie English, Brandi Zirk, and especially Laura Cruz for assistance with data analysis, including many hours of coding sessions. For sending raw data that contributed to the analyses presented in the Introduction, I send my appreciation to Meeta Patel.

For all their assistance, I thank very sincerely the members of the Parsons Research Center lab meetings: Dean Williams, Kate Saunders, Rafael Bejarano and again Adam. I have learned a great deal from our exchanges and have benefited greatly from our many discussions; both about this project in particular, and research in general. For Dean and Kate-I cannot offer enough thanks for allowing me the opportunity to come to Parsons and experience the opportunities that I have been given here. I am grateful for all the help and advice they have given over the past year that they had no obligation to do.

I also would very much like to thank Cindy Anderson, who has been my advisor over the past four years. Cindy, as well as the other faculty, took a chance on a student who had more passion than experience and for that I have nothing less than my future in behavior analysis to thank them for. I appreciate Cindy supporting many of my decisions, even when they led me down a path much different than anticipated. I have to thank her for allowing me to pursue opportunities outside her lab and practicum supervision and supporting these decisions. In addition to Dean and Cindy, I would also like to thank the other three members of the committee, Jennifer Margrett, Kent Parker, and Mike Perone, for their valuable feedback.

On a personal note, I would like to thank my parents, Michael and Debra Haag, who supported my decision to go to graduate school not only emotionally, but also financially. They, together with my sister, Kelly, and my grandparents, have allowed and 
encouraged me to "do what I have to do," despite their preference to have kept me close in recent years! Without your guidance, I would not have been able to achieve the high goals we set together when I was younger. As such, the completion of this project is, in part, dedicated to my family.

Christine Kim (my first friend in graduate school!) helped make this project possible long before it even existed by helping me in my first year (even my first days) of graduate school, to persist. And finally, I thank Adam again for his support and inspiration, and above all, friendship and caring. I look forward to many more years of happiness in our future! 
Figure 1. Results of data re-analysis of Patel, Ghezzi, Rapp, O’Flaherty, \& Titterington (2004) depicting percent of component elapsed prior to first occurrence of stereotypy..........................................

Figure 2. Percent of intervals scored with stereotypy during the analog functional analysis for Cam, Patrick, and Tommy.................................26

Figure 3. Percent of intervals scored with stereotypy (top) and percent of component elapsed prior to first stereotypical response (bottom) during Experiment 1 for

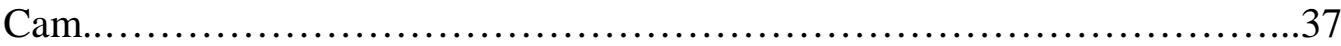

Figure 4. Percent of intervals scored with stereotypy (top) and percent of component elapsed prior to first stereotypical response (bottom) during Experiment 1 for Patrick

Figure 5. Percent of intervals scored with stereotypy (top) and percent of component elapsed prior to first stereotypical response (bottom) during Experiment 1 for Tommy

Figure 6. Percent of intervals scored with stereotypy in last six stable sessions of all conditions during Experiment 1 for Cam, Patrick, and Tommy

Figure 7. Percent of component elapsed prior to first stereotypical response in last six stable sessions of all conditions during Experiment 1 for Cam, Patrick, and Tommy .48

Figure 8. Percent of intervals scored with stereotypy (top) and mands per min (bottom) during Experiment 2 for Cam.........................................55

Figure 9. Percent of component elapsed prior to first mand (top) and percent of session spent in each component (bottom) during Experiment 2 for Cam..............58

Figure 10. Percent of intervals scored with stereotypy (top) and mands per min (bottom) during Experiment 2 for Patrick.

Figure 11. Percent of component elapsed prior to first mand (top) and percent of session spent in each component (bottom) during Experiment 2 for Patrick. .65 
vi

Figure 12. Percent of intervals scored with stereotypy (top) and mands per min (bottom) during Experiment 2 for Tommy.......................................68

Figure 13. Percent of component elapsed prior to first mand (top) and percent of session spent in each component (bottom) during Experiment 2 for Tommy..........71

Figure 14. Percent of intervals scored with stereotypy in last six stable sessions of all conditions during Experiment 2 for Cam, Patrick, and Tommy................74

Figure 15. Mands per min in last six stable sessions of all conditions during Experiment 2 for Cam, Patrick, and Tommy.......................................76 


\section{List of Tables}

Table 1. Mean and Range Occurrence, Nonoccurrence, and Total Agreement Scores....19

Table 2. Number of Sessions in Each Condition...................................32

Table 3. Mean and Range of the Results of the Last Six Sessions for Each Completed

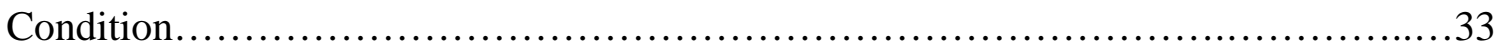




\section{viii}

Table of Contents

Page

Title Page........................................................................

Abstract..........................................................................

Acknowledgments............................................................

List of Figures..............................................................

List of Tables............................................................... vii

Chapter 1 - Overview......................................................1

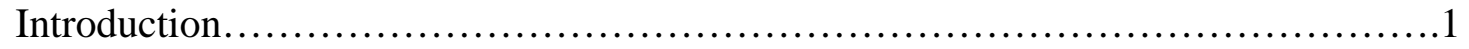

Stereotypy and Its Treatment as an Applied Problem..........................1

Literature Review......................................................

Differential Reinforcement of Manding...................................

Stimulus Control........................................................

Basic Research..................................................

Nonhuman research.....................................7

Human research...........................................8

Applied Research...............................................9

Adaptive responses (without punishment)..................10

Inappropriate responses (using punishment).................10

Statement of the Problem.................................................. 12

Chapter 2 - Experimental Methods and Results..................................15

Analog Functional Analysis............................................... 15

Method............................................................. 15

Participants....................................................

Cam..................................................16

Patrick..............................................16

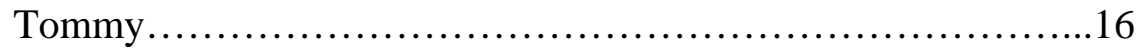

Setting .....................................................17 
Experimental Design.................................................

Operational Definitions, Data Collection, and Interobserver Agreement..17

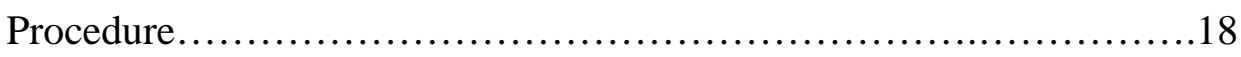

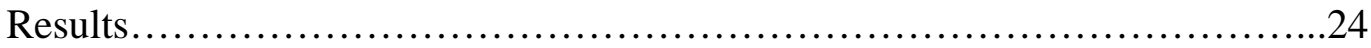

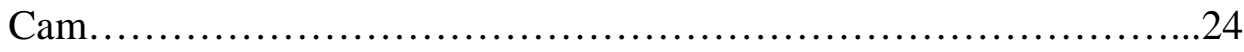

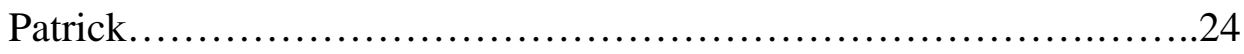

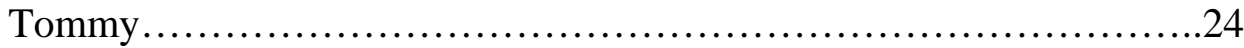

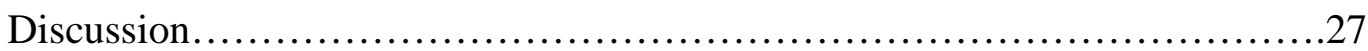

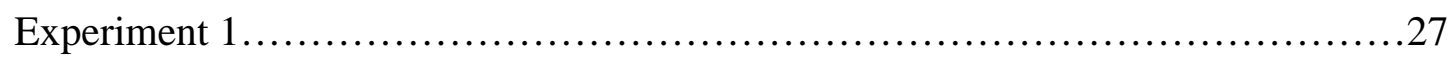

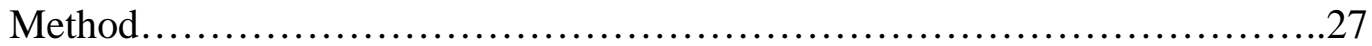

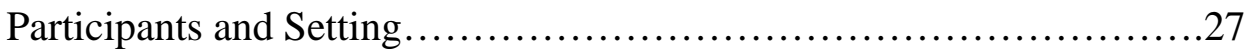

Experimental Design.............................................28

Operational Definitions, Data Collection, and Interobserver Agreement.28

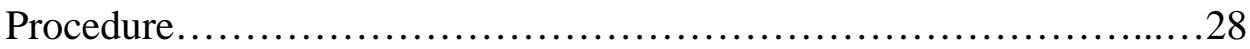

Baseline..............................................28

Stimulus-Control Training: Stereotypy........................29

Punishment selection...................................30

Manipulation of component duration.....................31

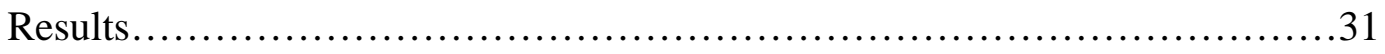

Unsuccessful Training Attempts.....................................31

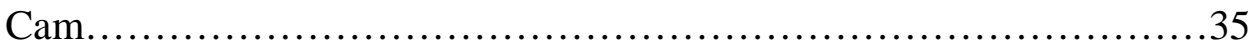

Baseline.................................................. 38

Stimulus-Control Training: Stereotypy.........................38

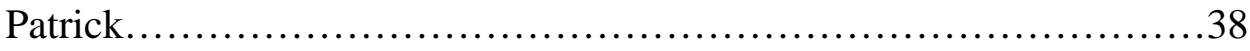

Baseline..................................................41

Stimulus-Control Training: Stereotypy .........................41

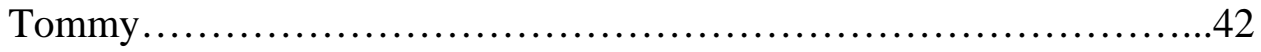

Baseline...................................................42

Stimulus-Control Training: Stereotypy.........................42

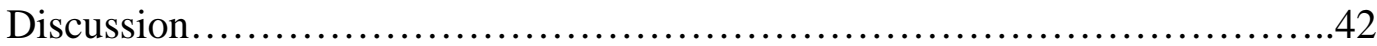




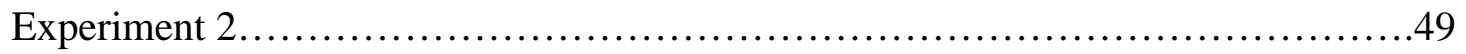

Method...........................................................49

Participants and Setting........................................49

Experimental Design.............................................49

Operational Definitions, Data Collection, and Interobserver Agreement.49

Procedure......................................................50

Baseline..................................................50

Differential Reinforcement of an Alternative Response..........50

Evaluation of the effects of training...................51

Stimulus-Control Training: Mands..........................51

Generalization Probes and Follow-Up Sessions.................52

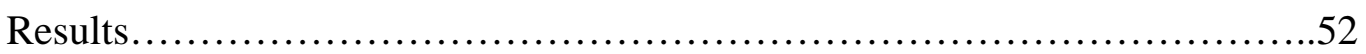

Cam.......................................................... 52

Baseline.................................................53

Differential Reinforcement of an Alternative Response.........53

Stimulus-Control Training: Mands..........................56

Patrick.........................................................59

Baseline................................................59

Differential Reinforcement of an Alternative Response.........59

Unsuccessful mand training attempts...................59

Successful mand training..........................60

Stimulus-Control Training: Mands..........................63

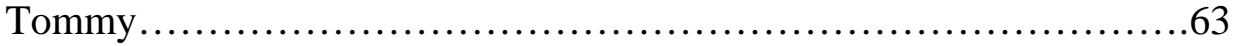

Baseline...............................................66

Differential Reinforcement of an Alternative Response..........66

Stimulus-Control Training: Mands........................66

Generalization Probes and Follow-Up Sessions...............69

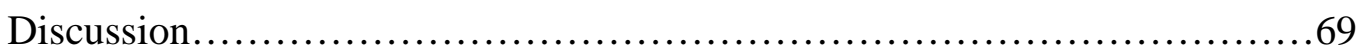


Chapter 3 - Conclusions....................................................... 72

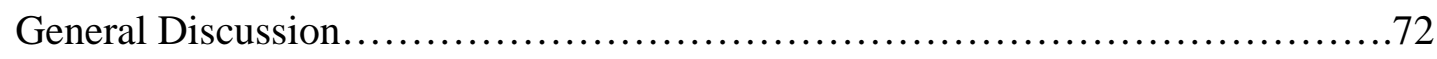

Differential Stereotypy and Identifying the Source of Stimulus Control.........72

Acquisition and Maintenance of an Appropriate Response......................78

Applied Value: Stimulus Control and Manding to Develop Interventions.......80

Practicality of the Stimuli and Utility of the Interventions...............81

Manding and Stimulus Control...................................... 81

The Necessity for Alternative Sources of Stimulation...................81

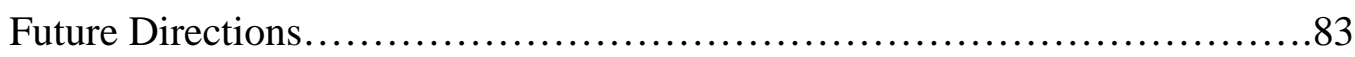

Conclusion: Impact of the Investigation of Stereotypy........................84

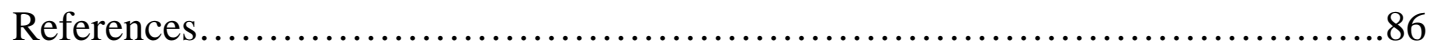


Chapter 1 - Overview

\section{Introduction}

Stereotypical behaviors are repetitive vocal or motor responses that are exhibited by individuals with autism, mental retardation, and mental illness, as well as typically developing individuals (e.g., Bodfish \& Lewis, 2002; Kennedy, 2002). These stereotypies, such as hand flapping and body rocking, frequently are referred to as "selfstimulatory” behaviors; however, this term prematurely assumes that, based on the topography of the response, one can determine that the behavior is sensory maintained. This conclusion is structural, rather than functional. Through the advent of various methods of functional assessment, applied behavior analysts have developed technologies to identify the variables maintaining responding. Such technologies have allowed for more functional definitions of behavior control. Sensory-maintained responses often are the most difficult to identify, as a response often is determined to be sensory-maintained only through the elimination of potential social reinforcers (e.g., Iwata et al., 1994). Because what is at issue in the present study are repetitive responses that likely are sensory maintained, terms referring to structure (e.g., stereotypy) and function (e.g., sensory-maintained responses) hereafter will be used interchangeably.

\section{Stereotypy and its Treatment as an Applied Problem}

Stereotypy is of concern to applied behavior analysts because depending on the rate and/or topography of the response, its occurrence in some cases can be detrimental to some individuals. Individuals who otherwise might be included in a less restrictive setting will continue to stand out as different from their peers, resulting in stigmatization for the individual and/or his or her family (Stricker, Miltenberger, Anderson, Tulloch, \& Deaver, 2002). These individuals also may be more difficult to teach, as engaging in stereotypy may interfere with the learning process (Lovaas, Newsom, \& Hickman, 1987). Third, as some research (e.g., Kennedy, 2002) suggests that stereotypy may evolve occasionally into self-injurious behavior, it may be advantageous to treat stereotypy before more serious problem behavior emerges.

Because stereotypy often is presumed to be sensory maintained, the occurrence of the response might also be said to be automatically reinforced (e.g., Iwata et al., 1994; 
Vollmer, 1994). In other words, the occurrence of the behavior itself serves to reinforce the behavior. As such, by completely eliminating the response from an individual's repertoire, researchers and practitioners may be removing unnecessarily a source of reinforcement, in some cases in an individual who has restricted interests and reinforcers (often indicated in persons with autism). Specifically, if the engagement in a stereotypical response is determined to be reinforcing, non-harmful, and inappropriate under some circumstances (but not others), it is unnecessary to suppress the response completely. It was indicated previously that all individuals engage in stereotypy in some form or another-however, societal standards often indicate when and where certain non-harmful stereotypies might be more appropriate, or at least "less inappropriate.” Obviously, any response that potentially could cause harm never is appropriate and should be eliminated.

Although it is clear that stereotypical behavior is an important applied concern, determining the function of, and designing an intervention for, presumed sensorymaintained responses often is challenging. The obstacles in conclusively demonstrating a response to be sensory maintained, and then treating it functionally, emerges from the reportedly private nature of the reinforcement and the technological difficulties with manipulating such reinforcement (e.g., Iwata et al., 1994). When a response is maintained by socially mediated reinforcement (e.g., attention), interventions manipulating the response-contingent delivery of the reinforcer (e.g., extinction) or the value of the reinforcer (e.g., by altering establishing operations) can be arranged. Sensory reinforcers, however, presumably always are available to the individual and cannot be delivered or withheld as can other reinforcers. Several interventions have been used to treat sensorymaintained stereotypies, including differential reinforcement procedures (e.g., Vollmer, 1994), sensory extinction (e.g., Rincover, 1978), and punishment (e.g., Mazaleski, Iwata, Rodgers, Vollmer, \& Zarcone, 1994). Each of these interventions can be effective, but each has drawbacks as well.

Although differential reinforcement often is effective in reducing stereotypy, it may be difficult to identify a reinforcer that will compete effectively for the reinforcement available for engaging in the stereotypy. Similarly, sensory extinction (e.g., Rincover, 1978) is effective only if the specific reinforcer can be identified and then 
blocked or attenuated (e.g., a mitten for hand mouthing maintained by the tactile stimulation of the hand). Finally, although punishment is effective in suppressing sensory-maintained responding (e.g., Mazaleski et al., 1994), punishment procedures may not be desirable because their long-term use may have negative side effects (Matson \& DiLorenzo, 1984). Further, parents and teachers often report difficulty in consistently implementing punishment procedures (Cooper, Heron, \& Heward, 1987; Miltenberger, 1997). Finally, the use of intrusive punishment procedures often focuses attention on the individual and perhaps are more socially stigmatizing than the stereotypy itself (Mayer, 1995). For these reasons, if punishment initially is necessary to suppress stereotypy, it might be desirable eventually to withdraw it while maintaining treatment effects.

Punishment generally is considered to be more ethical if combined with a reinforcement procedure, such as differential reinforcement. With regard to sensorymaintained responding, if the target behavior is not dangerous to engage in (e.g., hand flapping as opposed to eye gouging), it might be permissible for the response to occur under certain more appropriate stimulus conditions (to have limited access to the reinforcer; e.g., alone in their bedroom). An individual then could be taught to request to engage in the behavior under certain stimulus situations. Two interventions that might be combined to achieve this goal are (a) the differential reinforcement of an alternative behavior (DRA; where the alternative response is a mand, or request), and (b) the establishment of stimulus control of problem behavior using inconspicuous and more socially appropriate punishment procedures.

Literature Review

\section{Differential Reinforcement of Manding}

Differential reinforcement of an alternative behavior (DRA) involves teaching and then reinforcing an (appropriate) alternative to problem behavior. Often, the appropriate alternative is a mand. A mand is distinct from other instances of verbal behavior in that the mand is reinforced by a consequence that is specified in the response (e.g., "hug, please"). Furthermore, the mand is emitted under the control of deprivation of the consequence stimulus, or, under the control of aversive stimulation (Skinner, 1957). One specific type of DRA is functional communication training (FCT; Carr \& Durand, 
1985). Functional communication training often is used to decrease inappropriate behavior and increase appropriate behavior.

Functional communication training typically consists of two steps, determining the function of problem behavior through a systematic functional assessment, and teaching an alternative, more appropriate response (i.e., mand) reinforced by delivery of the reinforcer maintaining problem behavior. For example, Carr and Durand (1985) taught two children who engaged in attention-maintained problem behavior a mand reinforced by attention delivery: “Am I doing good work?” Similarly, three children whose problem behavior was escape-maintained were taught the mand "I don't understand,” resulting in assistance. In both cases, there was a significant decrease in problem behavior and an increase in manding.

Functional communication training has been used most often in combination with other interventions, particularly extinction (e.g., Hagopian, Fisher, Thibault Sullivan, Acquisto, \& LeBlanc, 1998; Shukla \& Albin, 1996) or punishment (e.g., Hagopian et al.) of the problem behavior. Hagopian et al. reviewed 21 inpatient cases where participants exhibited various topographies of problem behavior across a number of different functions. Some participants were exposed to FCT-only conditions, almost all participants were exposed to FCT plus extinction conditions, and some were exposed to FCT plus punishment conditions; many were exposed to some or all of these combinations of interventions at different times. When FCT was applied with extinction, a $90 \%$ reduction in problem behavior was achieved in at least $41 \%$ of applications.

Functional communication training with punishment was effective in $90 \%$ of all participants with whom it was attempted.

Thus, FCT, in combination with other interventions, is effective for individuals exhibiting problem behavior maintained by attention (e.g., Carr \& Durand, 1985), access to tangibles (e.g., Hagopian et al., 1998), escape/avoidance (e.g., Lalli, Casey, \& Kates, 1995), and these factors in combination (e.g., Hagopian et al.). Additional data suggest that results generalize across settings and time (Durand \& Carr, 1991, 1992). Because sensory reinforcers cannot be withdrawn and delivered in the same manner in which 
social or tangible reinforcers can be manipulated, however, research has not focused on the utility of FCT for responding maintained by sensory reinforcement.

Nevertheless, in procedures very similar to those involved in FCT, DRA might be implemented to replace problem behavior that results in some reinforcer. One way in which mand training might be used with sensory-maintained responding is to teach the individual a mand for stimulus conditions in which it might be considered more permissible to engage in the sensory-maintained response (i.e., a condition in which the response would not be followed by a punisher). To do so, however, the problem behavior first must be brought under the control of some stimulus signaling that condition.

\section{Stimulus Control}

Basic behavioral research has determined that, through discrimination training, a response can be brought under stimulus control. In this discrimination training, a minimum of two stimuli are required, each of which is correlated with different consequences (e.g., Dinsmoor, 1995b). Stimulus control is evident when there is a higher probability of a response in the presence of one stimulus and a lower probability of occurrence in the presence of a different stimulus (e.g., Pierce \& Epling, 1995). Using such a description, stimulus control, or differential responding, can be accounted for by two explanations surrounding the source of the stimulus control. First, responding can be controlled by the consequence. For example, the occurrence of a punisher within a component serves as a discriminative stimulus that future punishers will be delivered in that component (e.g., Azrin \& Holz, 1966). The punishing stimulus can be abbreviated $S^{P}$ (O’Donnell, 2001; O’Donnell, Crosbie, Williams, \& Saunders, 2000). When responding is similar across two components until the consequence (here, the $\mathrm{S}^{\mathrm{P}}$ ) occurs and responding then is differentiated (here, decreases), responding is controlled by the consequent stimulus. Thus, any experimenter-arranged stimuli (e.g., stimuli correlated with different components of a multiple schedule) here have no effect over responding.

Conversely, if differential consequences are correlated consistently with arbitrary experimenter-specified discriminative stimuli (e.g., a red light with punishment of responding and a green light with reinforcement of responding), control eventually can be developed by the experimenter-arranged antecedent stimuli. Azrin and Holz (1966) 
indicated that the presentation of punishment in one circumstance "can be used to produce a discrimination between two stimulus situations” (p. 415). Here, if stimuli correlated with different contingencies are presented and responding then is differentiated prior to the first delivery of any consequences, responding is under the control of these experimenter-arranged "stimulus situations.” If only a reinforcement contingency is in effect, the correlated stimulus conditions generally are referred to as the $\mathrm{S}^{\mathrm{D}}$. If a punishment contingency is in effect, the correlated stimulus conditions are referred to as the $S^{\text {Dp }}$ (O’Donnell, 2001; O’Donnell et al., 2000). Thus, in a multiple schedule where a history of reinforcement is correlated with one of the stimuli and a history of punishment is correlated with the other stimulus, response suppression is observed in the latter. In this situation, the source of that stimulus control can either be control by the consequent stimuli (i.e., the $\mathrm{S}^{\mathrm{P}}$ ) or the antecedent experimenter-arranged stimulus (i.e., the $\mathrm{S}^{\mathrm{Dp}}$ ). Either of these stimuli can serve as the discriminative stimulus for responding, and thus simply examining differential response rates is not sufficient in determining which stimulus is the discriminative stimulus).

Therefore, empirical articles that use this term (i.e., stimulus control) while only measuring differential response rates generally do not uncover or specify the source of stimulus control (the exception would be if responding in a punishment component is suppressed to zero). Despite the applied implications (e.g., controlling responding in the absence of a social [punishing] agent; see Piazza, Hanley \& Fisher, 1996), applied researchers rarely determine the source of the stimulus control (e.g., Patel, Ghezzi, Rapp, O’Flaherty, \& Titterington, 2004). For example, when a child behaves one way in the presence of his father (i.e., appropriately) and another way in the presence of his mother (i.e., inappropriately), stimulus control is evident. If his father no longer has to deliver the punishers that were once necessary and his mere presence suppresses responding, he serves as a discriminative stimulus for a punishment contingency in effect. In this latter case, control by $\mathrm{S}^{\mathrm{Dp}}$ is evident.

To date, only a few studies on stimulus control with punishment have examined responding sufficiently to determine if control by the $S^{\mathrm{P}}$ or $\mathrm{S}^{\mathrm{Dp}}$ was obtained. Despite the lack of extensive research examining the source of stimulus control within the 
punishment literature, the investigation of related issues have been of scientific interest. For example, similar questions previously have been raised in the context of reinforcement procedures (e.g., Denney \& Neuringer, 1998). In these studies, discrimination between a reinforcement and extinction component, or two different reinforcement schedules, is examined. It then is determined if the responding is controlled by the experimenter-arranged discriminative stimulus, or, the first occurrence of the consequence for responding serves as the discriminative stimulus for future responding in that component. For the source of stimulus control to be determined, analyses beyond simple response-rate differences must be conducted. These analyses include examining latency to first response (if the schedule in effect is fixed ratio [FR] 1 especially), examining response rates before and after the first consequence occurs, or conducting tests of generalization (discussed below, Basic Research). The relevant research on stimulus control, particularly stimulus control and punishment, is reviewed below, along with a discussion as to whether control by $S^{\mathrm{P}}$ or $S^{\mathrm{Dp}}$ was examined. Basic Research

Much research has been conducted in the experimental analysis of behavior with regard to stimulus control and discrimination training (see Dinsmoor, 1995a, 1995b). Below, the basic research most relevant to the present discussion is reviewed. These studies have produced mixed results with regard to the degree to which responding can be brought under control of the $S^{\text {Dp }}$. Additionally, stimulus control either can be established through punishment (e.g., reinforcement of a response in one component and reinforcement and punishment in another; see the present Experiment 1) or extinction (that is, reinforcement of response in one component and extinction in the other; see the present Experiment 2). Because stimulus control using punishment is particularly understudied and misunderstood, and because it is most relevant to the present investigation, stimulus control and punishment research is focused upon.

Nonhuman research. In one of the earliest experiments on stimulus control and punishment, Honig and Slifka (1964) examined generalization gradients. Generalization gradients following punishment are depicted as a U-shaped function obtained in the absence of the programmed contingencies. The lowest response rates occur in the 
presence of the stimulus correlated with punishment, and the highest response rates occur in the presence of those stimuli most different from that stimulus. Intermediate response rates often are observed in the stimuli with values near that of the stimulus correlated with punishment. In this study, following complete suppression in the presence of one stimulus, punishment was discontinued and responding recovered, but not before a gradient was observed in the absence of delivery of the $\mathrm{S}^{\mathrm{P}}$, indicating some discriminative control by $\mathrm{S}^{\mathrm{Dp}}$, not merely control by $\mathrm{S}^{\mathrm{P}}$ (since it had been withdrawn).

In a study specifically examining the source of stimulus control using punishment, Weisman (1975) examined differential responding of pigeons across components. In the presence of the $\mathrm{S}^{\mathrm{D}}$, pigeons received reinforcement on a variable-interval (VI) schedule and, in the presence of the $S^{D p}$, received reinforcement on a VI schedule, plus punishment after each response. Testing under mixed and multiple schedules demonstrated relatively little control by the $S^{\mathrm{Dp}}$. Similar results have been found with humans in the laboratory (e.g., O’Donnell \& Crosbie, 1998).

Human research. O’Donnell and Crosbie (1998) examined stimulus control and generalization with conditioned punishment. In their Experiment 2, 10 different line lengths were presented on a computer (some of which were determined to be indiscriminable in Experiment 1). In the presence of all line lengths, a reinforcement contingency was in effect (i.e., a VI 60-s schedule). Once responding had stabilized in the presence of all line lengths, a punishment contingency was added in the presence of one stimulus. No generalization gradient was obtained and thus control by $S^{D p}$ was not achieved. Although response suppression was observed in the presence of the $S^{D p}$, because responding was suppressed in the punishment condition only after the initial point loss during that component-responding was not sensitive to antecedent control by line length, but rather was controlled by the $\mathrm{S}^{\mathrm{P}}$ when it occurred. Specifically, participants responded equally across components until the first consequence was contacted. Responding then was suppressed in the presence of $S^{\text {Dp }}$, but not in the presence of any other stimulus. When the component changed, responding commenced again regardless of the experimenter-arranged antecedent stimulus presented, until the consequence was contacted again. Further attempts made to gain control by the $S^{\text {Dp }}$ rather 
than the $\mathrm{S}^{\mathrm{P}}$ in Experiments 3 and 4 (delayed reinforcement and intermittent reinforcement, respectively), however, stimulus control by $S^{\text {Dp }}$ still was not obtained.

In a study by O'Donnell et al. (2000), an attempt again was made to control responding by the $S^{D p}$, rather than by the $S^{P}$. Responding in the presence of a line of a particular length was reinforced with points, but responding in the presence of the $S^{D p}$ included both a reinforcement contingency and a punishment contingency. In this study, all participants were exposed first to conditions of immediate point loss and then to conditions in which point loss was delayed. Instructional changes also were made from the studies by O'Donnell and Crosbie (1998) to attempt to obtain control by $S^{D p}$. Responding remained under stimulus control when punishment was delayed, demonstrating control by $S^{D p}$. When generalization testing was conducted, the participants responded most frequently to $\mathrm{S}^{\mathrm{D}}$ and similar line lengths and least frequently to $S^{\mathrm{Dp}}$ and similar line lengths. Thus, in a procedure where the punisher is presented immediately in the presence of $S^{\mathrm{Dp}}$ and then delayed or withdrawn, responding is more likely to be controlled by $S^{\mathrm{Dp}}$ (not the $\mathrm{S}^{\mathrm{P}}$ ). Rollings and Baumeister (1981) demonstrated similar findings, including a generalization gradient, after bringing the stereotypic behavior of two participants under the control of different colored lights.

In these aforementioned studies and other studies examining generalization, the focus of the experiment was to examine the degree to which response rates in the presence of a stimulus generalize to other stimuli, or, the degree to which there was a failure of stimulus control. Some studies also show, however, suppression of responding in the absence of a programmed consequence, demonstrating some control by the antecedent stimulus. In some cases, however, generalization is not desired, and responding restricted to certain stimulus conditions is the goal.

\section{Applied Research}

Related applied research involves the direct implementation of stimulus control procedures as an intervention for some clinically significant problem. Applied studies involve either an increase in some appropriate response and/or a decrease in some inappropriate response in certain environmental conditions. This area of research would differ from the basic research described above in that this research examines socially 
10

important questions that directly impact the subject under study (Baer, Wolf, \& Risley, 1968).

Adaptive responses (without punishment). Redd and Birnbrauer (1969) conducted an investigation with two boys with mental retardation using different adults as discriminative stimuli for the different schedules in effect. In the presence of the experimenter delivering response-dependent reinforcement, appropriate play increased relative to baseline. In the presence of the experimenter delivering response-independent reinforcement, responding equaled that of baseline. Furthermore, Fisher, Kuhn, and Thompson (1998) demonstrated with two participants that manding reinforced with different stimuli could be brought under the discriminative control of two cards. In one condition, a photograph indicated the availability of attention; in the other condition, a photograph indicated the availability of toys. Mands taught to be result in attention or toys were either reinforced or ignored, depending on the condition in effect. After training, mands occurred exclusively under relevant stimulus conditions, thus demonstrating stimulus control.

Inappropriate responses (using punishment). Woods (1983) brought inappropriate page flipping exhibited by a child with developmental disabilities under the control of book type by using a red triangle to indicate which books were “off limits.” Page flipping either was verbally praised and permitted to continue (in the presence of unmarked books) or interrupted and punished (in the presence of books marked with a red triangle). Responding increased, relative to baseline, in the presence of unmarked books, but decreased in the presence of marked books.

Piazza, Hanley, and Fisher (1996) determined that cigarette pica (oral consumption of any part of the cigarette) exhibited by an individual with developmental disabilities was maintained by the sensory reinforcement provided by nicotine. After attempting an unsuccessful treatment involving response-independent food delivery, Piazza et al. brought cigarette pica under stimulus control (i.e., pica was ignored in the presence of a yellow card and interrupted in the presence of a purple card). This control over the response was accomplished not only with the response-interruption procedure, but also with the noncontingent availability of food. Rates of cigarette pica were 
suppressed to zero in the purple-card component. After suppression was obtained, punishment was discontinued successfully in the presence of the purple card. Results also generalized to four novel settings using the purple card. Because pica did not occur and the $S^{P}$ was discontinued, pica was under the control of the $S^{D p}$ rather than the $S^{P}$. It is unclear how long suppression might be maintained over long periods of time with the withdrawal of the $S^{\mathrm{P}}$. Still, these results demonstrate clear control by the cards presented as antecedent stimuli and have important implications for interventions involving stimulus control.

Patel et al. (2004) replicated some of the findings of Piazza et al. (1996) with automatically reinforced, delayed echolalia. Echolalia is the repetitive repeating of a word or phrase previously heard. Delayed echolalia occurs when the repeated phrase does not occur immediately after the stimulus was presented, and often is in the form of scripting parts or all of a movie, commercial, or song. In this study, delayed echolalia was punished with a verbal reprimand (for two participants) or timeout (for one participant) in the presence of a red card, and there were no programmed consequences for echolalia in the presence of a green card or no card. Relative to baseline, echolalia was suppressed in the presence of the red card and increased or remained the same in the presence of the green card. Unlike the study by Piazza et al., however, the original punisher (i.e., verbal reprimands or timeout) never was withdrawn and complete suppression of problem behavior never occurred. Thus, it is unclear as to whether response suppression was due to the onset of the $S^{\mathrm{Dp}}$, or the first delivery of the $\mathrm{S}^{\mathrm{P}}$.

Sufficient analyses were not conducted in Patel et al. (2004) to make a distinction between control by the experimenter-arranged antecedent stimulus, or $\mathrm{S}^{\mathrm{Dp}}$, and control by the consequence, or $\mathrm{S}^{\mathrm{P}}$. For this reason and due to its relevance to the present investigation, real-time data from the study were obtained from its first author and reanalyzed by calculating the latency to the first stereotypical response in each component. If the first response occurred at approximately the same time in both red and green components and responding then subsided after the contingent delivery of the $\mathrm{S}^{\mathrm{P}}$ in the red component, control most likely was exerted by the $\mathrm{S}^{\mathrm{P}}$. Results of the re-analysis demonstrated that inconsistent and weak control, if any, was exerted by the $S^{D p}$. That is, 
12

fewer than half of the sessions demonstrated long latencies to respond in the presence of the red card (see Figure 1).

\section{Statement of the Problem}

There are several aspects of the aforementioned studies that occasioned the proposed investigation; however, two issues are most relevant to the research question. First, these studies suggest that sensory-maintained problem behavior can be brought under a form of stimulus control. In these cases, however, either an insufficient measure was used to determine the source of that stimulus control (i.e., control by $\mathrm{S}^{\mathrm{P}}$ or $\mathrm{S}^{\mathrm{Dp}}$; e.g., Patel et al., 2004), or the incorporation of multiple interventions obscured the role of the stimuli and effect of punishment (e.g., instructions and token economy, Frazier \& Williams, 1973; response-independent food, Piazza et al., 1996), or mixed findings were obtained (O’Donnell et al., 2000 vs. Weisman, 1983). Therefore, further investigations must be conducted to identify the source of the stimulus control: control by antecedent $\left(S^{\text {Dp }}\right)$ or consequent $\left(S^{P}\right)$ stimuli. Second, no appropriate alternative to engage in stereotypy ever has been taught whereby participants learn a mand resulting in a stimulus correlated with nonpunishment. That is, after responding was brought under stimulus control, the participant had no means of obtaining the reinforcer appropriately in either the study by Patel et al. or Piazza et al. Such an intervention might be ethically unacceptable in the study by Piazza et al. due to health concerns. Nevertheless, in the study by Patel et al., self-stimulatory behavior was brought under stimulus control, then participants themselves had no control (see Carr \& Durand, 1985) over the delivery of the green card or when to engage in self-stimulatory behavior. Such an intervention is warranted (when the behavior is not harmful) because participants have demonstrated a preference toward interventions where there is control over reinforcer delivery (e.g., a preference for FCT over response-independent delivery; Hanley, Piazza, Fisher, Contrucci, \& Maglieri, 1997). Thus, while not necessarily a limitation of these studies per se, the addition of such an intervention might be valuable.

The purpose of the current investigation was to replicate and extend the findings of Piazza et al. (1996) and Patel et al. (2004). It was assessed whether non-harmful selfstimulatory responding could be brought under stimulus control by initially using 
Next Page

Figure 1. Percent of session elapsed prior to first stereotypical response in STOP and GO components for participants in study by Patel et al., 2004. The top graph depicts the results for $\mathrm{Al}$. The solid vertical line separates training conditions: Stimulus-Control Training Conditions 1 and 2. Baseline and a return to baseline preceded Conditions 1 and 2, respectively (not shown). The middle and bottom graphs depict the results for the last and second-to-last conditions for Art and Brandon, respectively. 
Figure 1.

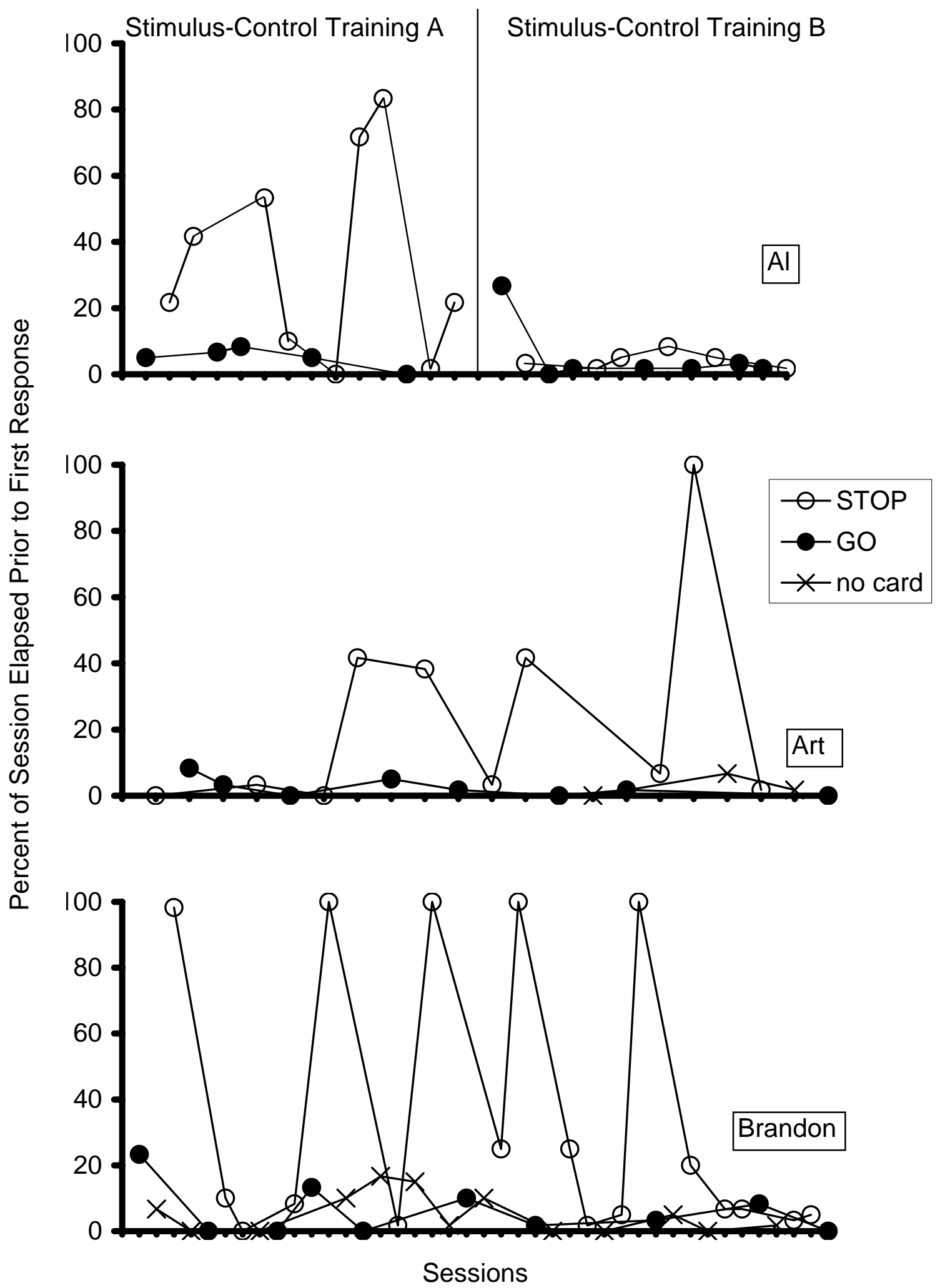


punishment procedures that subsequently were discontinued. Analyses other than differential occurrence of stereotypy were examined (i.e., latency measures) were conducted to determine whether any stimulus control observed was the result of control exerted by the $S^{\mathrm{Dp}}$ or $\mathrm{S}^{\mathrm{P}}$. In addition, the extent to which participants would acquire and maintain a mand for a stimulus correlated with nonpunishment of the targeted stereotypy $\left(S^{D}\right)$ was evaluated. Permitting the engagement of inappropriate behaviors can reinforce appropriate vocalizations (Charlop, Kurtz, \& Casey, 1990). Thus, if the $S^{\mathrm{D}}$ has conditioned reinforcing value due to its correlation with the unconsequated occurrence of self-stimulatory behaviors, manding resulting in the $S^{\mathrm{D}}$ should occur. Such an intervention would be useful not only because it would answer theoretical questions with regard to stimulus control and punishment, but also because it would have implications from a practical and ethical standpoint. Therefore, further procedures examining the applied value of mand acquisition in this case (i.e., stimulus control of manding) also must be examined.

Chapter 2 - Experimental Methods and Results

\section{ANALOG FUNCTIONAL ANALYSIS}

An analog functional analysis (Iwata, Dorsey, Slifer, Bauman, \& Richman, 1982/1994) was conducted to determine if participants' responding likely was sensory maintained, rather than maintained by social variables. A response often is considered to be sensory maintained when it occurs across most or all situations in an experimental analysis or in the absence of any social or tangible reinforcement. Only participants whose stereotypy was determined to be likely sensory maintained (that is, the social variables manipulated were excluded as potential reinforcers) were included in the experiment proper.

Method

Participants

Three adults with mental retardation participated. Each lived at a state-run residential facility for persons with developmental disabilities in a cottage with approximately 30 other individuals with developmental disabilities. Each participant 
engaged in a stereotypical response that was non-harmful but, at least occasionally, interfered with completion of tasks and/or socialization.

Cam

Cam was a 40-year-old male diagnosed with profound mental retardation and Down Syndrome. He communicated via spoken words and gestures, although some of his language was unintelligible or echolalic. Cam's score on the Peabody Picture Vocabulary Test, Third Edition (PPVT-III) placed him at the age equivalent of under one year. He had a history of seizures and received seizure medication throughout the course of this experiment.

Patrick

Patrick was a 54-year-old male diagnosed with severe mental retardation and rapid-cycling bipolar disorder. Patrick received $900 \mathrm{mg}$ of Lithium and $400 \mathrm{mg}$ of Tegretol per day throughout the study. He communicated through gestures and a few spoken words, but had few spontaneous or “original” vocalizations; Patrick predominantly exhibited delayed and immediate echolalia. His score on the PPVT-III also placed him at the age equivalent of under one year. Consistent with a diagnosis of bipolar disorder, there were many days during which Patrick's vocational staff indicated that he was extremely depressed. On those days, Patrick displayed no echolalia or other vocalizations, did not participate in previously enjoyed activities, and did not exhibit much, if any, stereotypy. He also would leave the lab, a behavior that rarely occurred

otherwise. As such, the decision was made not to conduct research sessions on those days when his staff indicated and the primary investigator observed independently that he was depressed (i.e., not engaging in those behaviors identified above). In total, Patrick missed 14 days due to the presentation of his mood disorder.

\section{Tommy}

Tommy was a 45-year-old male with autistic-like tendencies and severe mental retardation. Tommy also was profoundly deaf and legally blind, though the exact nature of his visual impairment was undetermined. Tommy had no expressive language and reportedly communicated through a few gestures, though no such communication was observed during the course of the experiment. Due to his hearing impairment, Tommy 
was unable to be tested on the PPVT-III and many standardized tests. His speech therapist reported he used very few rudimentary signs, which he mainly echoed. Tommy could not read lips, nor could he understand American Sign Language. Tommy received $5 \mathrm{mg}$ of Loxitane twice daily throughout the course of the study.

\section{Setting}

Sessions were conducted in a laboratory equipped with stimuli relevant to the condition, a one-way mirror, and video- and audio-recording equipment in an adjacent room located behind the mirror.

\section{Experimental Design}

The study consisted of five conditions that alternated in a pseudorandom fashion across sessions. A multielement design was used to demonstrate functional control. All sessions were $10 \mathrm{~min}$ in duration. Two to six sessions were conducted per day for each participant. Sessions were conducted five days per week with few exceptions, and the time of day was held constant for each participant.

Operational Definitions, Data Collection, and Interobserver Agreement

Stereotypy was defined individually for each participant. Cam’s targeted stereotypy was finger manipulation. Finger manipulation was defined as moving two fingers back and forth repeatedly at or above waist-level while his head was oriented in the direction of his fingers and his eyes were open (i.e., he was looking at them). Patrick’s targeted stereotypy was repetitive line drawing, defined as drawing vertical lines on paper. Tommy’s targeted stereotypy was hand and arm flapping, defined as moving his arms or hand through the air repeatedly at or above waist-level by bending at the wrist or elbow. The following experimenter behaviors also were coded: attention delivery, defined as 3-5 s delivery of physical contact and/or a vocal statement (e.g., “Don’t do that” [attention condition, punishment delivery]; "You're playing nicely” [control condition]; tangible delivery, defined as the delivery of a preferred stimulus (e.g., cola; determined through caregiver report); tangible removal, defined as removal of the preferred stimulus from the participant; and prompts, defined as verbal, gestural, or physical guidance to complete a task (e.g., pointing, hand-over-hand prompting). 
All sessions were videotaped for later scoring. Data were collected either in vivo or via videotape and either by the use of a computer data-collection program, or using pen-and-paper methods. Stereotypy was coded using a partial-interval coding system across continuous 5-s intervals. Experimenter responses were coded as a frequency measure throughout the study.

Prior to initiating data collection, observers were trained to criterion. Training involved (either a verbal or written) presentation and explanation of definitions by the primary investigator and a demonstration by a trained observer, followed by practice sessions. During the practice sessions, observers coded sessions that would not be used for formal analysis. Prior to beginning data collection, observers reached a criterion of $80 \%$ or higher total agreement on all target responses (participant and experimenter) for three consecutive sessions.

Interobserver agreement was assessed in a minimum of 33\% of the sessions in each phase. Agreement for partial-interval measures (e.g., stereotypy) was calculated by partitioning sessions into 5-s intervals and comparing observer's records across intervals. Occurrence, nonoccurrence, and total agreement scores were calculated. Occurrence agreement was calculated by dividing the number of intervals both coders agreed that a response occurred by the number of intervals either coder scored an occurrence. Nonoccurrence agreement was calculated by dividing the number of intervals both coders agreed a response did not occur by the number of intervals either coder did not score a response. Total agreement was calculated by dividing the number of intervals coders agreed the response did and did not occur by the total number of intervals. All coefficients were multiplied by 100 to obtain a percent agreement score. Interobserver agreement scores for all participants are in Table 1.

\section{Procedure}

An analog functional analysis similar to that described by Iwata et al. (1982/1994) was conducted with all participants. It included at least five conditions: demand, attention, tangible, alone, and control. A sixth condition, the idiosyncratic stimuli condition, was included for Cam and Tommy. No single condition occurred twice in succession and at least four sessions were conducted in each condition. The functional 
Table 1.

Mean and Range Occurrence, Nonoccurrence, and Total Agreement Scores

\begin{tabular}{|c|c|c|c|c|c|c|}
\hline Participant & Condition & $\begin{array}{c}\% \\
\text { of Sessions }\end{array}$ & Response & $\begin{array}{c}\text { Type of } \\
\text { Agreement }\end{array}$ & $\begin{array}{c}\% \\
\text { Agree }\end{array}$ & Range \\
\hline \multirow[t]{41}{*}{ Cam } & Analog & 33.3 & stereotypy & Occ & 96.7 & $89.2-100$ \\
\hline & & & & NonOcc & 94.5 & $73-100$ \\
\hline & & & & Total & 98.1 & $91.7-100$ \\
\hline & & & tangible & Occ & 87.5 & N/A \\
\hline & & & delivery & NonOcc & 99.1 & N/A \\
\hline & & & & Total & 99.2 & N/A \\
\hline & & & tangible & Occ & 87.5 & N/A \\
\hline & & & removal & NonOcc & 99.1 & N/A \\
\hline & & & & Total & 99.2 & N/A \\
\hline & & & prompts & Осc & 98.7 & $97.4-100$ \\
\hline & & & & NonOcc & 99.5 & 98.9-100 \\
\hline & & & & Total & 99.6 & $99.2-100$ \\
\hline & & & compliance & Occ & 100 & $100-100$ \\
\hline & & & & NonOcc & 100 & $100-100$ \\
\hline & & & & Total & 100 & $100-100$ \\
\hline & & & attention & Occ & 100 & $100-100$ \\
\hline & & & & NonOcc & 100 & $100-100$ \\
\hline & & & & Total & 100 & $100-100$ \\
\hline & Baseline & 33.3 & stereotypy & Occ & 92.2 & 78.9-96.7 \\
\hline & & & & NonOcc & 88.6 & $76-95.6$ \\
\hline & & & & Total & 95.8 & $91.7-97.5$ \\
\hline & SCT:Stereotypy & 33.3 & stereotypy & Occ & 92.8 & 68.8-100 \\
\hline & & & & NonOcc & 96.4 & $93.8-100$ \\
\hline & & & & Total & 97.6 & $94.2-100$ \\
\hline & & & punisher & Occ & 82.1 & $0-100$ \\
\hline & & & & NonOcc & 99.6 & $96.7-100$ \\
\hline & & & & Total & 99.6 & $96.7-100$ \\
\hline & DRA & 33.3 & stereotypy & Occ & 84.5 & $0-100$ \\
\hline & & & & NonOcc & 98.3 & $92.2-100$ \\
\hline & & & & Total & 98.7 & $95-100$ \\
\hline & & & punisher & Осс & 95.5 & $50-100$ \\
\hline & & & & NonOcc & 99.9 & $99.2-100$ \\
\hline & & & & Total & 99.9 & $99.2-100$ \\
\hline & & & mand & & 90.9 & $0-100$ \\
\hline & SCT: Mands & 34.8 & stereotypy & Occ & 92.9 & $60-100$ \\
\hline & & & & NonOcc & 98.6 & $97.5-100$ \\
\hline & & & & Total & 98.9 & 97.9-100 \\
\hline & & & punisher & Осc & 90.6 & $0-100$ \\
\hline & & & & NonOcc & 99.9 & $99.2-100$ \\
\hline & & & & Total & 99.9 & $99.2-100$ \\
\hline & & & mand & & 98.4 & 75-100 \\
\hline
\end{tabular}


Table 1. (Continued.)

Mean and Range Occurrence, Nonoccurrence, and Total Agreement Scores

\begin{tabular}{|c|c|c|c|c|c|c|}
\hline Participant & Condition & $\begin{array}{c}\% \\
\text { of Sessions }\end{array}$ & Response & $\begin{array}{c}\text { Type of } \\
\text { Agreement }\end{array}$ & $\begin{array}{c}\% \\
\text { Agree }\end{array}$ & Range \\
\hline \multirow[t]{35}{*}{ Patrick } & Analog & 33.3 & stereotypy & Осс & 90.3 & $50-100$ \\
\hline & & & & NonOcc & 90.5 & $68.8-100$ \\
\hline & & & & Total & 97.6 & $91.7-100$ \\
\hline & & & tangible & Occ & 100 & N/A \\
\hline & & & delivery & NonOcc & 100 & N/A \\
\hline & & & & Total & 100 & N/A \\
\hline & & & tangible & Occ & 100 & N/A \\
\hline & & & removal & NonOcc & 100 & N/A \\
\hline & & & & Total & 100 & N/A \\
\hline & & & prompts & Occ & 89.8 & N/A \\
\hline & & & & NonOcc & 98.1 & N/A \\
\hline & & & & Total & 98.3 & N/A \\
\hline & & & compliance & Occ & 90 & N/A \\
\hline & & & & NonOcc & 99.1 & N/A \\
\hline & & & & Total & 99.2 & N/A \\
\hline & & & attention & Occ & 88 & $80-100$ \\
\hline & & & & NonOcc & 97.8 & $91.7-100$ \\
\hline & & & & Total & 99.2 & $98.3-100$ \\
\hline & Baseline & 49.2 & stereotypy & Occ & 96.7 & $90.5-100$ \\
\hline & & & & NonOcc & 90.3 & $76.5-100$ \\
\hline & & & & Total & 97.4 & $92.5-100$ \\
\hline & SCT:Stereotypy & y 33.3 & stereotypy & Occ & 91.8 & $35.1-100$ \\
\hline & & & & NonOcc & 97.2 & $78.6-100$ \\
\hline & & & & Total & 98.1 & $81-100$ \\
\hline & & & punisher & Осс & 89.9 & $50-100$ \\
\hline & & & & NonOcc & 99.4 & $95.7-100$ \\
\hline & & & & Total & 99.4 & $96-100$ \\
\hline & DRA & 33.3 & stereotypy & Occ & 86.8 & N/A \\
\hline & & & & NonOcc & 81.5 & N/A \\
\hline & & & & Total & 91.7 & N/A \\
\hline & & & mand & & 100 & N/A \\
\hline & SCT: Mands & 34.8 & stereotypy & Occ & 97.7 & $93.2-100$ \\
\hline & & & & NonOcc & 98.7 & $96.2-100$ \\
\hline & & & & Total & 99.2 & $97.5-100$ \\
\hline & & & mand & & 89.3 & $80-100$ \\
\hline
\end{tabular}


Table 1. (Continued.)

Mean and Range Occurrence, Nonoccurrence, and Total Agreement Scores

\begin{tabular}{|c|c|c|c|c|c|c|}
\hline Participant & Condition & $\begin{array}{c}\% \\
\text { of Sessions }\end{array}$ & Response & $\begin{array}{c}\text { Type of } \\
\text { Agreement }\end{array}$ & $\begin{array}{c}\% \\
\text { Agree } \\
\end{array}$ & Range \\
\hline \multirow[t]{41}{*}{ Tommy } & \multirow[t]{18}{*}{ Analog } & \multirow[t]{9}{*}{33.3} & \multirow[t]{3}{*}{ stereotypy } & Occ & 84.2 & $77.4-92.6$ \\
\hline & & & & NonOcc & 74 & $30.8-97.8$ \\
\hline & & & & Total & 91.1 & $94.7-100$ \\
\hline & & & \multirow{3}{*}{$\begin{array}{l}\text { tangible } \\
\text { delivery }\end{array}$} & Occ & 97.4 & $94.7-100$ \\
\hline & & & & NonOcc & 99.5 & $99-100$ \\
\hline & & & & Total & 99.6 & $99.2-100$ \\
\hline & & & \multirow{3}{*}{$\begin{array}{l}\text { tangible } \\
\text { removal }\end{array}$} & Occ & 91.2 & $82.4-100$ \\
\hline & & & & NonOcc & 98.9 & $97.8-100$ \\
\hline & & & & Total & 98.8 & $97.5-100$ \\
\hline & & \multirow[t]{9}{*}{33.3} & \multirow[t]{3}{*}{ prompts } & Осc & 87.1 & 81.8-92.3 \\
\hline & & & & NonOcc & 97 & $96.1-97.9$ \\
\hline & & & & Total & 97.5 & $96.7-98.3$ \\
\hline & & & \multirow[t]{3}{*}{ compliance } & Occ & 86.6 & $85.7-87.5$ \\
\hline & & & & NonOcc & 98.6 & $98.1-99.1$ \\
\hline & & & & Total & 98.8 & $98.3-99.2$ \\
\hline & & & \multirow[t]{3}{*}{ attention } & Occ & 90.7 & $88.5-100$ \\
\hline & & & & NonOcc & 96.8 & $91.9-100$ \\
\hline & & & & Total & 97.8 & $95-100$ \\
\hline & \multirow[t]{3}{*}{ Baseline } & \multirow[t]{3}{*}{33.3} & \multirow{3}{*}{ stereotypy } & Occ & 91.2 & $78.6-100$ \\
\hline & & & & NonOcc & 78.1 & $41.7-100$ \\
\hline & & & & Total & 93.5 & 87.5-100 \\
\hline & \multirow[t]{6}{*}{ SCT:Stereotypy } & \multirow[t]{6}{*}{33.3} & \multirow[t]{3}{*}{ stereotypy } & Occ & 80.6 & $50-95$ \\
\hline & & & & NonOcc & 89.1 & 81.1-99 \\
\hline & & & & Total & 92.6 & 84.2-99.2 \\
\hline & & & \multirow[t]{3}{*}{ punisher } & Occ & 84.6 & $0-100$ \\
\hline & & & & NonOcc & 99.7 & $98.3-100$ \\
\hline & & & & Total & 99.7 & $98.3-100$ \\
\hline & \multirow[t]{7}{*}{ DRA } & \multirow[t]{7}{*}{33.3} & \multirow[t]{3}{*}{ stereotypy } & Occ & 79.4 & 64.9-89 \\
\hline & & & & NonOcc & 88.7 & $79.2-99.2$ \\
\hline & & & & Total & 93.1 & 87.5-99.2 \\
\hline & & & \multirow[t]{3}{*}{ punisher } & Осс & 77.8 & $0-100$ \\
\hline & & & & NonOcc & 99.7 & $98.3-100$ \\
\hline & & & & Total & 99.7 & $98.3-100$ \\
\hline & & & mand & & 100 & $100-100$ \\
\hline & \multirow[t]{7}{*}{ SCT: Mands } & \multirow[t]{7}{*}{34.8} & \multirow[t]{3}{*}{ stereotypy } & Occ & 93.7 & 80-97.9 \\
\hline & & & & NonOcc & 96.2 & 85.7-98.9 \\
\hline & & & & Total & 98.3 & $96.7-99.2$ \\
\hline & & & \multirow[t]{3}{*}{ punisher } & Occ & 100 & $100-100$ \\
\hline & & & & NonOcc & 100 & $100-100$ \\
\hline & & & & Total & 100 & $100-100$ \\
\hline & & & mand & & 97.4 & $90.9-100$ \\
\hline
\end{tabular}


Table 1. (Continued.)

Mean and Range Occurrence, Nonoccurrence, and Total Agreement Scores

\begin{tabular}{|c|c|c|c|c|c|c|}
\hline \multirow[b]{2}{*}{ Participant } & \multirow[b]{2}{*}{ Condition } & \multirow[b]{2}{*}{ of Sessions } & \multicolumn{2}{|l|}{$\%$} & \multicolumn{2}{|c|}{ Type of } \\
\hline & & & Response & Agreement & Agree & Range \\
\hline \multirow{17}{*}{$\begin{array}{l}\text { Tommy } \\
\text { (continued) }\end{array}$} & cottage probe & 33.3 & stereotypy & Occ & 96.4 & N/A \\
\hline & & & & NonOcc & 69.2 & N/A \\
\hline & & & & Total & 96.7 & N/A \\
\hline & cottage tx & 50 & stereotypy & Осс & 94 & $88-100$ \\
\hline & & & & NonOcc & 96.1 & $92.1-100$ \\
\hline & & & & Total & 97.5 & $95-100$ \\
\hline & & & punisher & Occ & 100 & $100-100$ \\
\hline & & & & NonOcc & 100 & $100-100$ \\
\hline & & & & Total & 100 & $100-100$ \\
\hline & & & mand & & 97.5 & $95-100$ \\
\hline & follow up & 33.3 & stereotypy & Осс & 93 & N/A \\
\hline & & & & Nocc & 96.3 & N/A \\
\hline & & & & Total & 97.5 & N/A \\
\hline & & & punisher & Occ & 100 & N/A \\
\hline & & & & NonOcc & 100 & N/A \\
\hline & & & & Total & 100 & N/A \\
\hline & & & mand & & 100 & N/A \\
\hline
\end{tabular}


analysis continued until this minimum criterion had been met and responding was judged to be stable by visual inspection.

The purpose of the demand condition was to determine if the targeted response was maintained by escape or avoidance of tasks. In the demand condition, the experimenter presented pre-academic demands using a three-step prompting procedure consisting of sequential verbal, gestural, and physical prompts. The participant received brief verbal praise upon successful completion of the task following either a verbal or gestural prompt (i.e., compliance). If the participant exhibited a targeted response, the task was withdrawn for $20 \mathrm{~s}$ and the experimenter turned away from the participant. After the 20-s interval, a new demand was presented. All behaviors were ignored during the 20s interval. Because Tommy was deaf, for him the verbal prompt was omitted and gestural prompts were presented twice, with the second being more intrusive than the first (usually by touching Tommy and pointing the second time). The purpose of the attention condition was to determine if the targeted response was maintained by access to attention. At the beginning of the attention condition, the experimenter told the participant, "Play with your toys, I have some work to do,” and looked at a magazine. Contingent upon and immediately following a targeted response for Cam and Patrick, the experimenter delivered a brief vocal reprimand (e.g., "Stop doing that,”) and for Tommy, signed and stated "stop" while facing him. All other behaviors were ignored. The purpose of the tangible condition was to determine if the targeted response was maintained by access to preferred tangibles. In the tangible condition, the participant was given a preferred tangible for two min prior to the start of the session. When the session began, the item was removed. Immediately following the targeted response, the tangible was returned to the participant for $20 \mathrm{~s}$. The tangibles used were music for Patrick and Cam, and soda for Tommy. The purpose of the alone condition was to contribute to the notion that the targeted response may be maintained by sensory reinforcement. In the alone condition, the participant was in the room alone. Tangibles were not available and there were no programmed consequences for responding. The control condition served as a control for the absence of demands, the presence of and attention from the experimenter, and the presence of tangibles. In the control condition, the experimenter was present and 
preferred tangibles were available. The experimenter delivered verbal attention (i.e., praise) every $20 \mathrm{~s}$. If the targeted response was occurring at the programmed time to deliver attention, attention was delayed until $5 \mathrm{~s}$ beyond the termination of the targeted response. The purpose of the idiosyncratic stimuli condition was to determine if the targeted response occurred only or mainly in the presence of some idiosyncratic stimulus (i.e., a television). This condition was conducted for Cam and Tommy based on staff report that they might engage in more stereotypy in the presence of the television. In this condition, the experimenter was present, there were no programmed consequences for the targeted response, and the television was on continuously.

Results

Cam

Results of the analog functional analysis conducted with Cam are shown in the top graph of Figure 2. With the exception of the attention condition, stereotypical responding was undifferentiated; however, the occurrence of stereotypy was somewhat variable. If a response is maintained by sensory reinforcement, one pattern of responding that might be observed is that responding occurs at similar levels across conditions, including the alone condition, in which social consequences are not manipulated-this is the pattern that was observed with Cam (suppression in the attention condition suggested that it was possible that verbal reprimands functioned as a punisher).

\section{Patrick}

As shown in the middle graph of Figure 2, stereotypical responding occurred in most intervals across all conditions except the attention condition. These results suggest that stereotypy was not maintained by any social positive or negative reinforcers and likely was sensory maintained. The results also suggest that attention might possibly punish stereotypy (although later training demonstrated that attention did not punish responding, thus it is not used as the $\mathrm{S}^{\mathrm{P}}$ in Experiment 1).

Tommy

As shown in the bottom graph of Figure 2, stereotypy was observed across all conditions. The occurrence of stereotypy was somewhat variable across conditions but occurred most often in the alone, idiosyncratic, and control conditions; in which there 
Next Page

Figure 2. Percent of intervals scored with stereotypy during the analog functional analysis for all three participants: Cam, Patrick, and Tommy in the top, middle, and bottom graphs, respectively. 
Figure 2.
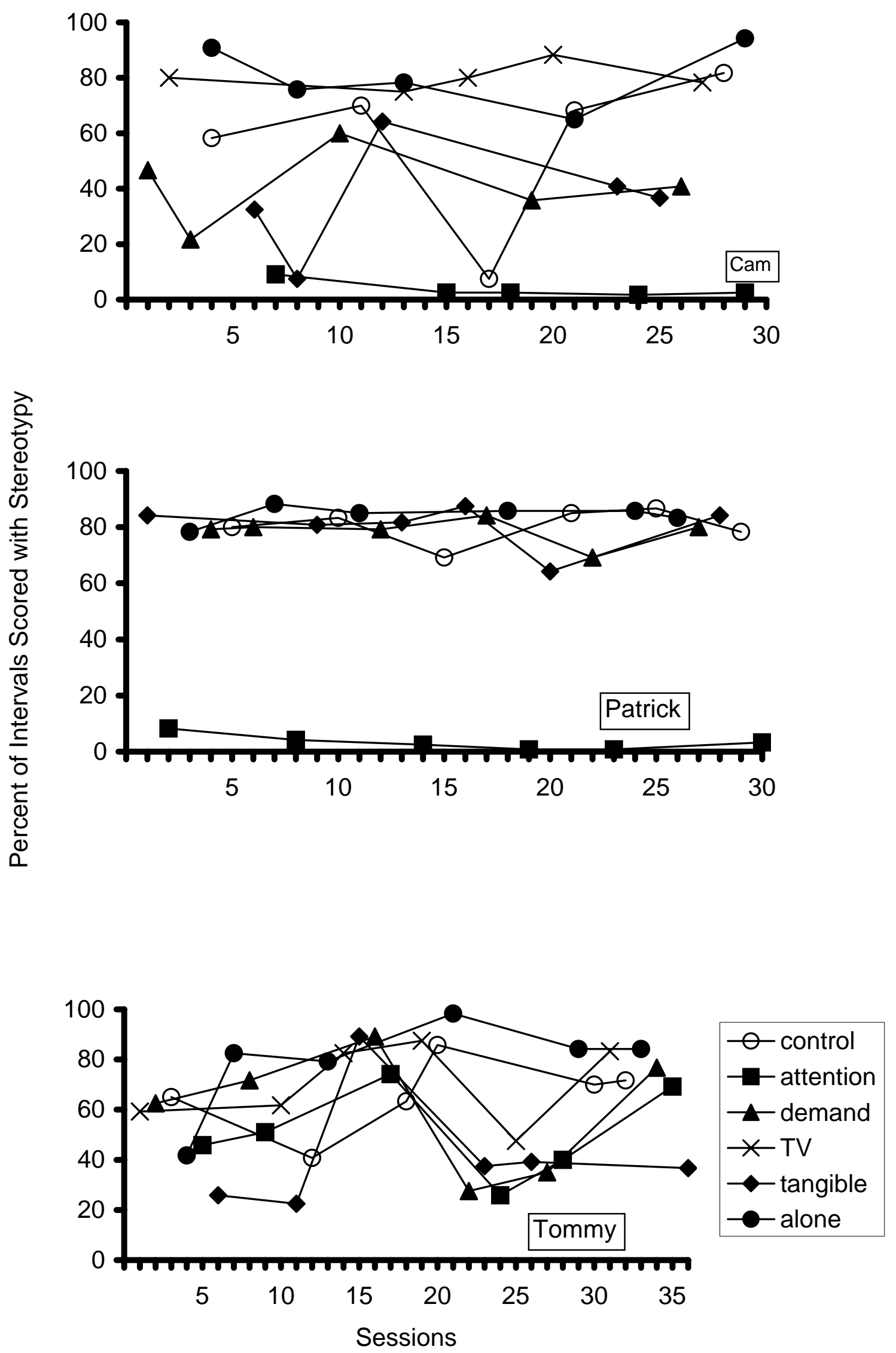
were no programmed consequences for responding. Thus, the results of the functional analysis suggest that stereotypy may be sensory maintained.

\section{Discussion}

As such, all three participants participated in the two subsequent experiments for further analysis of stereotypy. It is noteworthy that the present results do not lead necessarily to the conclusion that the stereotypy was sensory maintained. Instead, because no sensory reinforcers were manipulated, it is more accurate to conclude that the social variables manipulated in the analog functional analysis were excluded as potential maintaining reinforcers for stereotypy. However, reaching the conclusion of possible sensory-maintained behavior based on results such as these (i.e., high rates in the alone condition or undifferentiated responding across conditions), while not ideal, is traditional within the field of applied behavior analysis (e.g., Iwata et al., 1994). Once this conclusion was reached, the purpose of the first experiment was to determine if the stereotypy then would come under stimulus control.

\section{EXPERIMENT 1}

The purpose of Experiment 1 was to replicate the findings that stereotypical responding could be brought under stimulus control (Patel et al., 2004). Furthermore, additional procedures (i.e., removal of the contingent $S^{P}$ ) and analyses (i.e., measurement of percent of component elapsed prior to first stereotypical response) were conducted to determine if responding was controlled by the $S^{\text {Dp }}$, after their relation to the consequent stimulus, the $\mathrm{S}^{\mathrm{P}}$, was established.

Method

Baseline measures of targeted stereotypy were recorded in the presence and absence of specific environmental stimuli that later would or would not be paired with punishment. After completion of baseline, stimulus-control training began and the targeted response was punished in the presence of one stimulus condition but not the other.

\section{Participants and Setting}

The participants and setting were the same as in the analog functional analysis. 


\section{Experimental Design}

The experimental design was a multiple schedule embedded in an AB design, where " $A$ " was baseline and "B" was stimulus-control training of stereotypy.

Operational Definitions, Data Collection, and Interobserver Agreement

For all participants, punishment was defined as the onset of the predetermined stimulus. Stimuli used for each participant will be defined below. Punishment for Cam and Tommy at the termination of the experiment (i.e., when stimulus control was achieved) was defined as 1-s response interruption (i.e., briefly touching his hands). For Patrick, punishment was defined as a 10-s marker removal and hands-down prompt (i.e., the markers were withdrawn and Patrick was prompted to put his hands on his lap or the table; if he attempted to move them within $10 \mathrm{~s}$, he was prompted to return them).

\section{Procedure}

All sessions were 10 min in length unless otherwise noted. Each condition had a minimum of 15 sessions. Stability was considered by examining the last six sessions of stereotypical responding, and the percent of session elapsed prior to first response (in sessions other than baseline). Conditions were changed when responding was stable via visual inspection, or a slight trend in the data was evident in the direction opposite that which was expected in the next condition. Also, if the data in the last six sessions were variable, conditions could change if, when comparing these sessions to previous sessions, this variability was typical of the response and the participant.

Baseline

The experimenter was present during all baseline sessions. There were no tangibles available during sessions conducted with Cam. Tangible items were present for the remaining participants: paper and markers were present for Patrick, a television with a Sesame Street movie was present for Tommy, and a table game (Connect 4) and several toys for both Patrick and Tommy.

Baseline sessions were conduced using a multiple schedule, with each of two components lasting $5 \mathrm{~min}$ of the 10 -min session. There were no programmed consequences for stereotypy in either component. The different components of the schedule were signaled by specific stimuli. For Cam, different components were signaled 
by the color of the wall (red or blue), whether or not he was facing the experimenter (when he was facing the red wall, he was also facing the experimenter; when he was facing the blue wall, his back was toward the experimenter), and a verbal cue at the start of the component (“alone time” vs. “I’m here now”). For Patrick, different components were signaled by the presence or absence of a wristband placed on his wrist and a verbal cue at the start of the component ("wristband on” vs. "wristband off”). For Tommy, different components were signaled only by the presence or absence of a wristband placed on his wrist. These particular signals were selected due to their inconspicuous (i.e., wristbands) and/or practical (i.e., wristbands and presence/absence of another person) nature and through trial and error after some stimuli failed to establish differential responding (Cam) or control by $S^{\text {Dp }}$ (Patrick). Failed attempts are detailed below.

The order of the components was pseudorandom (i.e., random to the extent to which it was possible while still maintaining equal exposure to each order) and determined by a coin toss with two restrictions: (a) any one order occurred no more than three times consecutively and (b) twelve consecutive sessions consisted of one block of sessions; only one-half of the sessions in each block could have the components presented in the same order. The stimuli required to mand were present during baseline sessions (except for Patrick, for whom several failed attempts [detailed later] were made to teach him a mand). Baseline was terminated after a minimum of 15 sessions had been conducted during which either an upward trend or no trend was evident in the last six sessions.

\section{Stimulus-Control Training: Stereotypy}

The procedures involving the order of the presentation of the components were identical to those described above. In this condition, however, the occurrence of stereotypy was followed by a punisher in one component (signaled by the $\mathrm{S}^{\mathrm{Dp}}$; hereafter, the STOP component). For Cam, the STOP component was the one in which he was facing the experimenter and red wall. For the other two participants, the STOP component was the one in which they were not wearing the wristband. There were no programmed consequences for the occurrence of the target stereotypy in the other 
component; hereafter, the GO component. The GO component was signaled by the presence of the SD (i.e., the experimenter and blue wall for Cam and the wristband for Patrick and Tommy).

Punishment selection. The initial choice of a stimulus to evaluate as a punisher was determined based on the results of the attention condition in the functional analysis. If the rates were lower in this condition relative to other conditions, response-contingent reprimands first were used as a punishment procedure (Cam and Patrick), with other punishers used as necessary (see definitions above). As Tommy’s stereotypy was not suppressed in the attention condition, response interruption was used as the consequence for stereotypy because it was perceived to be a socially acceptable consequence. Response interruption involved briefly (i.e., for $1 \mathrm{~s}$ ) touching Tommy’s hands contingent upon stereotypy. For Cam, verbal reprimands suppressed responding across components and resulted in emotional outbursts (e.g., crying, complaining, pulling the experimenter's clothing). Thus, response interruption (as defined above) was attempted. For Patrick, neither verbal reprimands nor 1-s response interruption were successful in reducing stereotypy to a clinically significant level, so 10-s response interruption and marker removal were attempted. If the punisher eventually used physically prohibited stereotypy (i.e., marker removal for $10 \mathrm{~s}$ for Patrick), the duration of the punishment delivery was added to the STOP component for each time the punisher was employed, sometimes resulting in sessions longer than $10 \mathrm{~min}$.

Manipulation of component duration. After suppression of responding was observed in the STOP (but not GO) components, component duration was shortened to $2.5 \mathrm{~min}$. Thus, there were a total of four components per session. The purpose of this step was to establish that stimulus control, if observed, was the result of control by $S^{D p}$, and not by the passage of time. There were a total of six possible component orders (e.g., STOP-STOP-GO-GO, GO-STOP-GO-STOP). The order of the components was determined by drawing orders out of a pile in a random-selection-without-replacement format. This condition remained in effect until four criteria were met: (a) each of the six orders had been presented at least once, (b) there was no overlap in the results of the components (in any dependent measure) in five of the last six sessions, (c) responding 
had stabilized (as judged by visual inspection of the percent of intervals in which stereotypy was scored and latency until the first response), and (d) at least half of the component had elapsed prior to responding in the STOP component(s). With Cam, an attempt was made to withdraw the FR1 delivery of the $S^{P}$. The purpose was to see if presentation of the $S^{\text {Dp }}$ alone was sufficient to suppress responding.

\section{Results}

In addition to measuring percent of intervals scored with a stereotypical response, manding was measured across all conditions (though it was not taught, and thus not expected to occur). Also, the percent of the component that had elapsed prior to the first “relevant” response also was measured during the training condition to further evaluate the extent to which stimulus control was achieved. (Relevant response refers to the response that is being brought under stimulus control in each phase; in Experiment 1, the relevant response is stereotypy because it is stereotypy that is being brought under stimulus control). Although measuring latency to first response would have provided similar information, such data were more difficult to interpret because component durations differed throughout the experiment. Again, the number of sessions per condition for each participant is presented in Table 2. Means and ranges for the last six sessions of each condition are presented in Table 3. The results for each participant are presented individually below.

\section{Unsuccessful Training Attempts}

Although stimulus control over stereotypy was immediately achieved with Tommy, several attempts were necessary with both Cam and Patrick due to either a lack of suppression in the STOP component (Patrick) or suppression in both components (Cam). The attempts are summarized below and more detailed information is available upon request.

Three unsuccessful attempts to achieve stimulus control over stereotypy prior to DRA were conducted with Cam. Stimuli used in each attempt were as follows: visual stimuli (red/green cards), tactile stimuli (wristband on/off), and auditory stimuli (music on/off) in a total of 98 sessions. Stimuli initially were chosen because they would be inconspicuous to the casual observer (e.g., wristband) or could be faded easily to be 
Table 2.

Number of Sessions in Each Condition

Participant $\quad$ Condition/Experiment $\quad \begin{gathered}\text { Number } \\ \text { of Sessions }\end{gathered}$

Cam

Analog 30

Pretraining baseline A/EXP1 21

Pretraining SCT A/EXP1 25

Pretraining baseline B/EXP1 7

Pretraining baseline C/EXP1 25

Pretraining SCT C/EXP1 9

Baseline/EXP1 33

SCT: Stereotypy/EXP1 81

DRA (with prompts) $\mathrm{a} / \mathrm{EXP} 2 \quad 6$

DRA (independent)/EXP2 33

SCT: Mands/EXP2 46

$\begin{array}{lll}\text { Patrick } & \text { Analog } & 30\end{array}$

Pretraining baseline/EXP1 17

Pretraining SCT/EXP1 18

Baseline/EXP1 21

SCT: Stereotypy/EXP1 130

DRA (with prompts) ${ }^{\mathrm{a}} / \mathrm{EXP} 2 \quad 4^{\mathrm{b}}$

DRA (independent)/EXP2 3

SCT: Mands/EXP2 16

Tommy Analog $\quad 36$

Baseline/EXP1 29

SCT: Stereotypy/EXP1 38

DRA (with prompts) $/$ EXP2 2

DRA (independent)/EXP2 25

SCT: Mands/EXP2 21

Cottage probe baseline 3

Cottage probe treatment 4

One-month follow up 2

Three-month follow up 1

${ }^{\mathrm{a}}$ These data are not shown on Figures.

bThese sessions show only the number of sessions required to teach Patrick's one acquired mand. The number of sessions for unsuccessful attempts to teach Patrick other mands is not shown here. 
Table 3.

Mean and Range of the Results of the Last Six Sessions for Each Completed Condition

\begin{tabular}{|c|c|c|c|c|c|}
\hline Participant & Condition & $\begin{array}{l}\text { Dependent } \\
\text { Measure }\end{array}$ & STOP/GO & Mean & Range \\
\hline \multirow[t]{11}{*}{ Cam } & Baseline & \% stereotypy & STOP & 66.4 & $48.3-86.7$ \\
\hline & & & GO & 76.9 & 38.3-91.6 \\
\hline & SCT: Stereotypy & \% stereotypy & STOP & 0.6 & $0-3.3$ \\
\hline & & & GO & 74.2 & 48.3-91.7 \\
\hline & & \% elapsed & STOP & 94.5 & 66.7-100 \\
\hline & & & GO & 6.7 & $0-20$ \\
\hline & DRA & \% stereotypy & STOP & 2.3 & $0-5.9$ \\
\hline & & & GO & 56.9 & $39.1-77$ \\
\hline & & mands & STOP & $2.3 \mathrm{r} / \mathrm{min}$ & $1.1-3.5 \mathrm{r} / \mathrm{min}$ \\
\hline & & & GO & $0 \mathrm{r} / \mathrm{min}$ & $\mathrm{N} / \mathrm{A}$ \\
\hline & & \% session & GO & 67.1 & $53.3-73.3$ \\
\hline \multirow[t]{24}{*}{ Patrick } & Baseline & \% stereotypy & STOP & 74.5 & $70-80$ \\
\hline & & & GO & 75 & $60-83.3$ \\
\hline & SCT: Stereotypy & \% stereotypy & STOP & 0.9 & $0-1.7$ \\
\hline & & & GO & 71.4 & 46.7-88.3 \\
\hline & & \% elapsed & STOP & 82.2 & $60-100$ \\
\hline & & & GO & 17.8 & $3.3-36.7$ \\
\hline & DRA & \% stereotypy & STOP & N/A & $\mathrm{N} / \mathrm{A}$ \\
\hline & & & GO & 71.1 & $68.3-72.7$ \\
\hline & & mands & STOP & $8 \mathrm{r} / \mathrm{min}$ & $4.4-11.3 \mathrm{r} / \mathrm{min}$ \\
\hline & & & GO & $0 \mathrm{r} / \mathrm{min}$ & N/A \\
\hline & & \% session & $\mathrm{GO}$ & 87.5 & $81.7-91.7$ \\
\hline & SCT: Mands & \% stereotypy & STOP & & \\
\hline & & & $\begin{array}{l}\text { (FR1mand) } \\
\text { STOP }\end{array}$ & N/A & N/A \\
\hline & & & (mandEXT) & N/A & $\mathrm{N} / \mathrm{A}$ \\
\hline & & & $\mathrm{GO}$ & 75.8 & 69.8-81.1 \\
\hline & & mands & STOP & & \\
\hline & & & $\begin{array}{l}\text { (FR1mand) } \\
\text { STOP }\end{array}$ & \multicolumn{2}{|c|}{$8.4 \mathrm{r} / \mathrm{min} 7.1-10 \mathrm{r} / \mathrm{min}$} \\
\hline & & & (mandEXT) & $0 \mathrm{r} / \mathrm{min}$ & N/A \\
\hline & & & $\mathrm{GO}$ & $0 \mathrm{r} / \mathrm{min}$ & N/A \\
\hline & & \% elapsed & STOP & & \\
\hline & & & $\begin{array}{l}\text { (FR1mand) } \\
\text { STOP }\end{array}$ & 3.3 & 3.3-3.3 \\
\hline & & & (mandEXT) & 100 & $100-100$ \\
\hline & & & $\mathrm{GO}$ & 100 & $100-100$ \\
\hline & & $\%$ session & GO & 44.2 & 43.3-45 \\
\hline
\end{tabular}


Table 3. (Continued.)

Mean and Range of the Results of the Last Six Sessions for Each Completed Condition

\begin{tabular}{|c|c|c|c|c|c|}
\hline Participant & Condition & $\begin{array}{l}\text { Dependent } \\
\text { Measure }\end{array}$ & STOP/GO & Mean & Range \\
\hline \multirow[t]{23}{*}{ Tommy } & Baseline & \% stereotypy & STOP & 60.6 & $40-75$ \\
\hline & & & GO & 65.3 & $36.7-83.3$ \\
\hline & SCT: Stereotypy & \% stereotypy & STOP & 0.6 & $0-1.7$ \\
\hline & & & GO & 62.2 & $18.3-88.3$ \\
\hline & & \% elapsed & STOP & 94.5 & $70-100$ \\
\hline & & & GO & 7.8 & $0-43.3$ \\
\hline & DRA & \% stereotypy & STOP & 2.1 & $0-3.4$ \\
\hline & & & GO & 79.3 & 67.9-91.2 \\
\hline & & mands & STOP & $6.9 \mathrm{r} / \mathrm{mil}$ & $6-7.9 \mathrm{r} / \mathrm{min}$ \\
\hline & & & GO & $0 \mathrm{r} / \mathrm{min}$ & N/A \\
\hline & & \% session & GO & 73.3 & 70-75 \\
\hline & SCT: Mands & \% stereotypy & STOP & & \\
\hline & & & $\begin{array}{l}\text { (FR1mand) } \\
\text { STOP }\end{array}$ & 1.3 & $0-7.7$ \\
\hline & & & (mandEXT) & 0.6 & $0-1.7$ \\
\hline & & & $\mathrm{GO}$ & 82.1 & $70.5-89.6$ \\
\hline & & mands & STOP & & \\
\hline & & & $\begin{array}{l}\text { (FR1mand) } \\
\text { STOP }\end{array}$ & $9.2 \mathrm{r} / \mathrm{mil}$ & $7.7-10 \mathrm{r} / \mathrm{min}$ \\
\hline & & & (mandEXT) & $0 \mathrm{r} / \mathrm{min}$ & N/A \\
\hline & & & GO & $0 \mathrm{r} / \mathrm{min}$ & N/A \\
\hline & & \% elapsed & $\begin{array}{l}\text { STOP } \\
\text { (FR1mand) }\end{array}$ & 3.3 & 3.3-3.3 \\
\hline & & & $\begin{array}{l}\text { SIUP } \\
\text { (mandEXT) }\end{array}$ & 100 & $100-100$ \\
\hline & & & GO & 100 & $100-100$ \\
\hline & & \% session & GO & 39 & $36.7-40$ \\
\hline
\end{tabular}

Note. The data presented are for the following measures: percent of intervals scored with a stereotypical response, mands per min, percent of component elapsed prior to first response, and percent of session spent in the GO component, respectively. The names of these measures are abbreviated above for brevity in the table. 
inconspicuous (e.g., cards). In the first attempt (cards), differential responding across stimulus conditions was observed, but the findings were not consistent and prompts included only to help in differentiating the components were not faded successfully. In the second attempt (wristband), response suppression occurred across both components in baseline (despite no programmed contingencies for stereotypy in the GO component). In the third attempt (music), responding was almost suppressed completely in both components following the introduction of punishment. The different types of stimuli employed (i.e., visual, tactile, and auditory) were chosen in an attempt to find stimuli to which Cam would more likely attend. Specifically, other researchers (e.g., Dube \& McIlvane, 2003) have stated that participants sometimes attend to only certain aspects of complex stimuli. For Cam, stereotypy did not come under stimulus control until the fourth attempt, possibly because he was not attending to the experimentally manipulated stimuli.

With Patrick, one unsuccessful attempt to achieve stimulus control occurred prior to the results reported in this paper (red/green cards) in 35 sessions. Although differential responding was observed in the two components following introduction of a punishment procedure in one component, stereotypy was only partially suppressed (35.2\% reduction from baseline) and, in fact, was not suppressed to the degree to which would be acceptable for an applied intervention. In addition, differential latencies to first response were not observed and, as such, it was presumed that there was control by the $S^{\text {Dp }}$, rather than the $S^{D}$. Thus in an attempt to bring stereotypy under the control of the $S^{D}$, the $S^{D}$ was changed from cards to wristbands, each of which was equally inconspicuous.

\section{Cam}

The results of the stimulus-control training are listed in Table 3 and shown in the Figure 3. Percent of intervals scored with a stereotypical response is shown in the top graph and percent of session elapsed prior to first (relevant) response is depicted in the bottom graph. In sessions where there was more than one of each component type (i.e., GO, STOP), the mean percent delay to first response was presented in the figures. 
Next Page

Figure 3. The top graph depicts the percent of intervals scored with stereotypy during Experiment 1 for Cam. Solid vertical lines represent condition changes. Dotted vertical lines indicate a change in the punishment contingency (sessions with the contingency present denoted by "SP," in all other conditions). The numbers indicate length of the GO components. The bottom graph depicts the percent of each component elapsed prior to the first occurrence of stereotypy in the SCT: stereotypy condition of Experiment 1 for Cam. Wherever more than one of any type of component occurs per session, the mean for that session is presented. The numbers indicate length of the GO components. 
Figure 3.
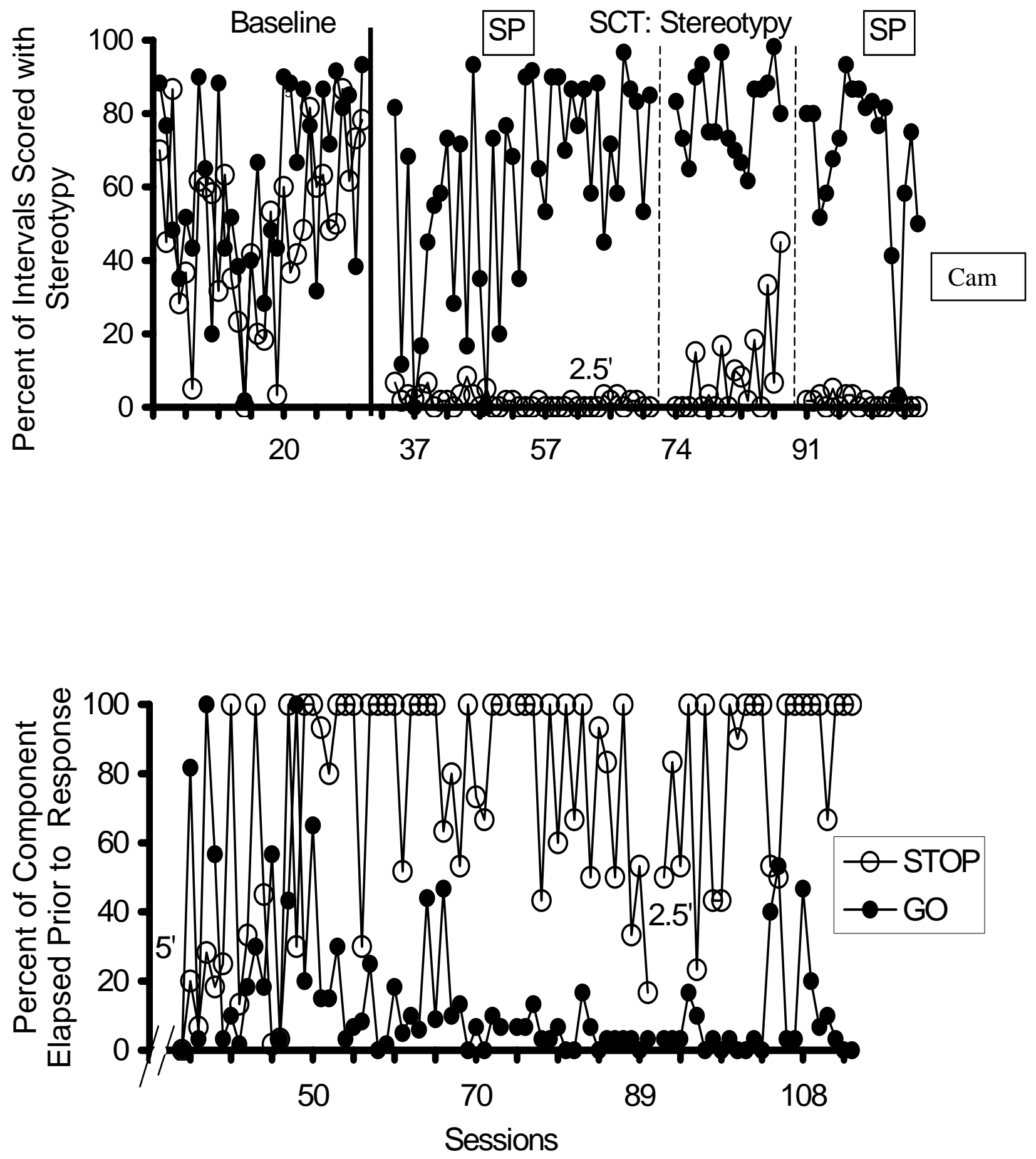


\section{Baseline}

Percent of intervals scored with stereotypy are depicted in the top graph of Figure 3. Occurrence of stereotypy was variable in baseline, but was undifferentiated across components.

Stimulus-Control Training: Stereotypy

As shown in the top graph of Figure 3, when punishment was made contingent upon stereotypy in the STOP component, differentiation was observed almost immediately. Responding remained differentiated when component duration was shortened to $2.5 \mathrm{~min}$ (indicated by 2.5' on the figure). To evaluate whether responding would remain suppressed in STOP in the absence of punishment, the punishment procedure was withdrawn. Within 13 sessions, however, stereotypy increased nearly to baseline levels, so the $\mathrm{S}^{\mathrm{P}}$ was reinstated. As expected, no manding occurred in this condition.

As shown in the bottom graph of Figure 3, although there initially was a great deal of overlap with regard to the percent of each component that elapsed prior to the occurrence of the first stereotypical response; after approximately 16 sessions, stereotypy began to occur relatively early in the session during the GO component, and late in the session (if at all) in STOP. (Components where no response occurred were scored as $100 \%$ of component elapsed; components where responding occurred in the first five seconds were scored as $0 \%$ of component elapsed.) During the last six sessions of stimulus-control training of stereotypy (2.5-min components), an average of $94.5 \%$ of intervals in STOP components elapsed before the first stereotypical response occurred. In contrast, an average of $6.7 \%$ of intervals elapsed prior to the first stereotypical response in the GO component.

\section{Patrick}

Results are listed in Table 3 and shown in Figure 4. The top graph shows the percent of intervals scored with a stereotypical response and the bottom graph shows the percent of each component elapsed prior to the first relevant response. 
Next Page

Figure 4. The top graph depicts the percent of intervals scored with stereotypy during Experiment 1 for Patrick. Solid vertical lines represent condition changes. Dotted vertical lines indicate a change in the punishment contingency. The numbers indicate length of the GO components. The dotted vertical line indicates where the punishing stimulus was changed. The numbers indicate length of the GO components. The bottom graph depicts the percent of each component elapsed prior to the first occurrence of stereotypy in the SCT: stereotypy condition of Experiment 1 for Patrick. Wherever more than one of any type of component occurs per session, the mean for that session is presented. 
Figure 4.
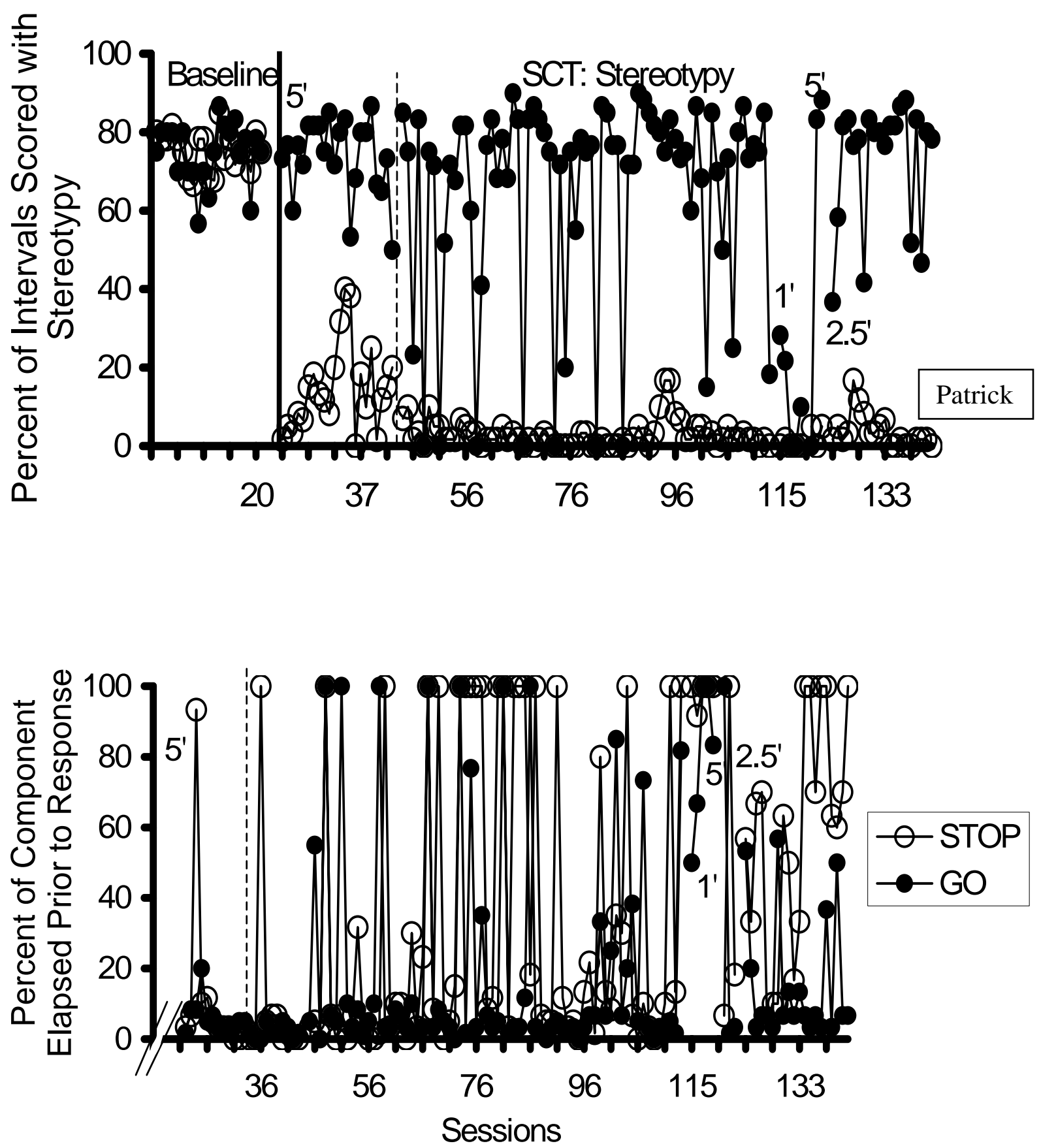


\section{Baseline}

As shown in the top graph of Figure 4, stereotypy was high and stable in baseline. There also was no systematic differentiation across (wristband vs. no wristband) components. As expected, no manding occurred in baseline. Stimulus-Control Training: Stereotypy

The top graph of Figure 4 shows that when the $S^{\mathrm{P}}$ was delivered contingent upon stereotypy in the 5-min STOP component, there was differentiation between STOP and GO components almost immediately. However, at Session 44, it was determined that the existing $\mathrm{S}^{\mathrm{P}}$ was not going to reduce responding in the STOP component to clinically significant levels. Thus, the 1-s response interruption procedure was changed to a 10 -s response prevention procedure (i.e., marker removal and physical prompt). This change resulted in rapid suppression of stereotypy in the STOP component.

Although stereotypy occurred relatively infrequently in STOP, there also were many sessions during which stereotypy did not occur during GO components, suggesting that it was possible that there was a problem obtaining strong stimulus control. Stereotypy occurred during GO components primarily when GO preceded STOP in a given session; if STOP was the first component, stereotypy sometimes was not observed in GO. To maximize the number of learning opportunities, then, the component duration was shortened to 1 min (indicated by the 1' on the figures). However, stereotypy then decreased in the GO component, due perhaps to the amount of time Patrick spent getting his markers and paper arranged to emit the stereotypical response. After a brief reversal to $5 \mathrm{~min}$, the component length then was increased to $2.5 \mathrm{~min}$ (indicated by the 5 ' and 2.5' respectively on the figures). Intervals scored with stereotypy remained somewhat variable in the GO components, although no sessions with zero responding in the GO component were observed. Again, no manding occurred in this condition.

As shown in the bottom graph of Figure 4, the latency until stereotypy occurred was quite variable prior to changing component duration to $2.5 \mathrm{~min}$, suggesting that stereotypy was not under antecedent control. When the component duration ultimately was made $2.5 \mathrm{~min}$, the latency to stereotypy increased in the STOP component and decreased in the GO component. 
Results for Tommy's stimulus control procedure are listed in Table 3 and depicted in Figure 5. Percent of intervals scored with a stereotypical response is shown in the top graph of Figure 5 and percent of component elapsed prior to first relevant response is shown in the bottom graph of Figure 5.

Baseline

As shown in the top graph of Figure 5, stereotypical responding was variable in baseline. As expected, there was no systematic differentiation in the occurrence of stereotypy across components, and no manding occurred in baseline.

Stimulus-Control Training: Stereotypy

As shown in the top graph of Figure 5, when component lengths were $5 \mathrm{~min}$, there was differentiation in stereotypy between STOP and GO components almost immediately after the introduction of the contingent $\mathrm{S}^{\mathrm{P}}$, and there was no overlap in responding. No significant changes were observed when component duration was shortened to $2.5 \mathrm{~min}$ No manding occurred in this condition.

As shown in the bottom graph of Figure 5, there initially was some overlap in response latencies once the contingent $S^{\mathrm{P}}$ was presented in the STOP component. However, the relative latencies in each component soon were highly differentiated and remained so when the component duration was changed to $2.5 \mathrm{~min}$.

\section{Discussion}

Each participant responded differentially in the STOP and GO components after punishment was implemented in the STOP component. For clarity, the last six (stable) sessions of each condition are presented in the top, middle, and bottom graphs of Figure 6 for Cam, Patrick, and Tommy, respectively. Furthermore, the differential occurrence of stereotypy across components in these last six sessions was the result of control by the $S^{D p}$ in each case. The results depicting the percent of component elapsed prior to first response for these sessions appears in Figure 7. After stereotypical responding was under stimulus control and control by $S^{\text {Dp }}$ was established, Experiment 2 was conducted to determine if, in the presence of the $\mathrm{S}^{\mathrm{Dp}}$ (STOP), participants would acquire a mand resulting in access to the $\mathrm{S}^{\mathrm{D}}(\mathrm{GO})$. 
Next Page

Figure 5. The top graph depicts the percent of intervals scored with stereotypy during Experiment 1 for Tommy. Solid vertical lines represent condition changes. Dotted vertical lines indicate a change in the punishment contingency. The numbers indicate length of the GO components. The numbers indicate length of the GO components. The bottom graph depicts the percent of each component elapsed prior to the first occurrence of stereotypy in the SCT: stereotypy condition of Experiment 1 for Tommy. Wherever more than one of any type of component occurs per session, the mean for that session is presented. 
Figure 5.
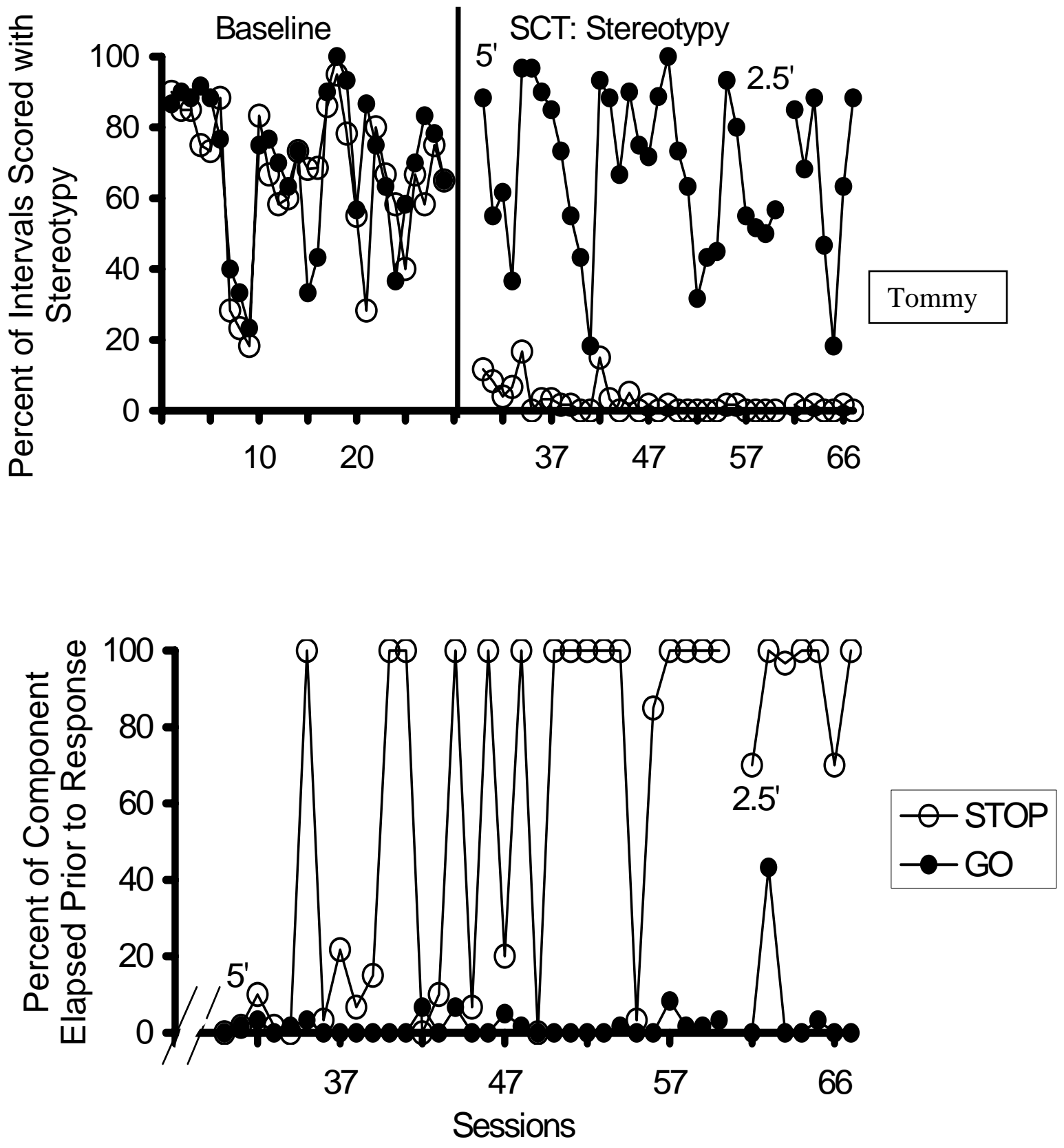
Next Page

Figure 6. Percent of intervals scored with stereotypy for the last six stable sessions of each condition of Experiment 1. Results in the top, middle, and bottom graphs are for Cam, Patrick, and Tommy, respectively. 
Figure 6.
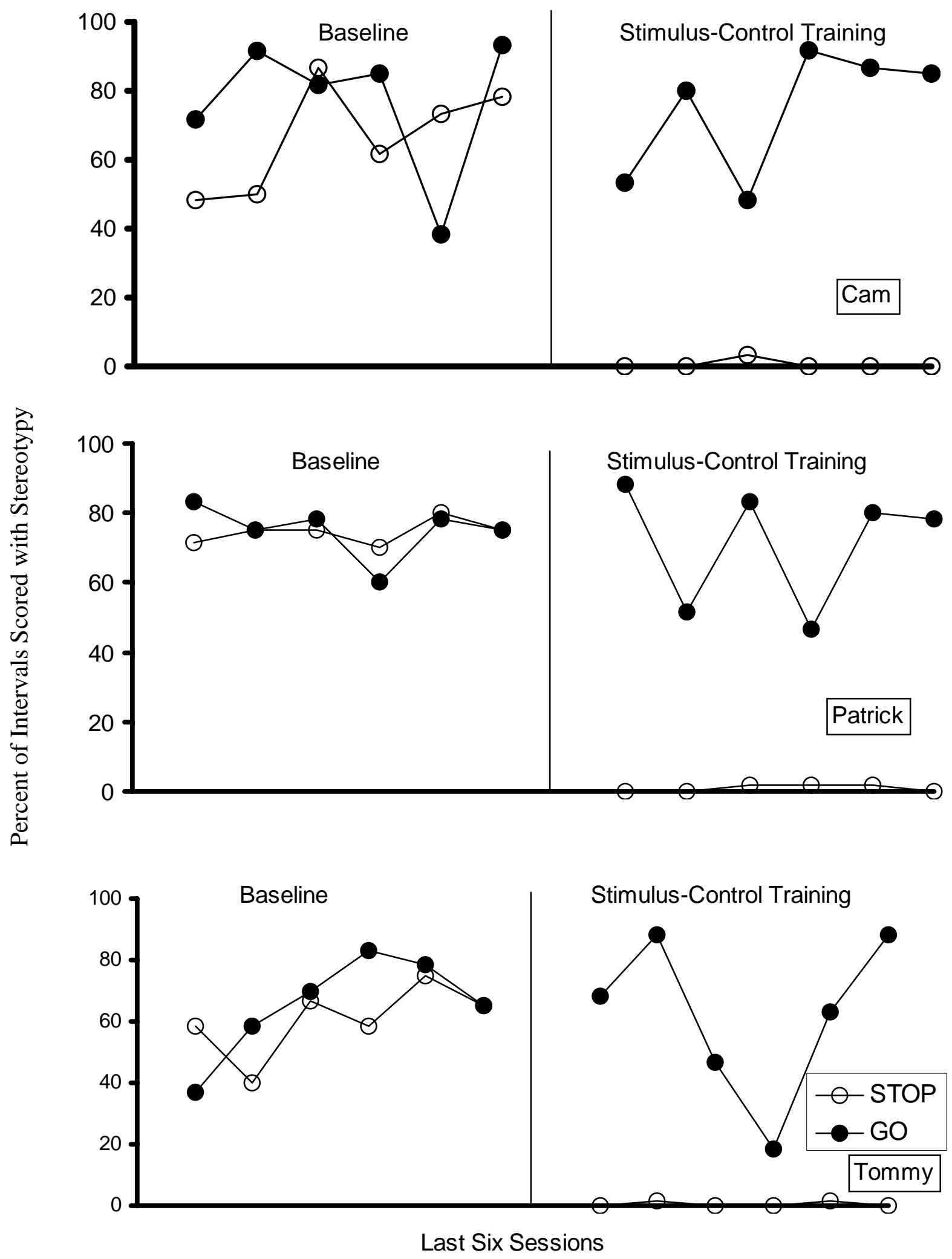
Next Page

Figure 7. Percent of component elapsed prior to first stereotypical response for the last six stable sessions of the training condition (i.e., stimulus control of stereotypy) of Experiment 1. Results in the top, middle, and bottom graphs are for Cam, Patrick, and Tommy, respectively. 
Figure 7.
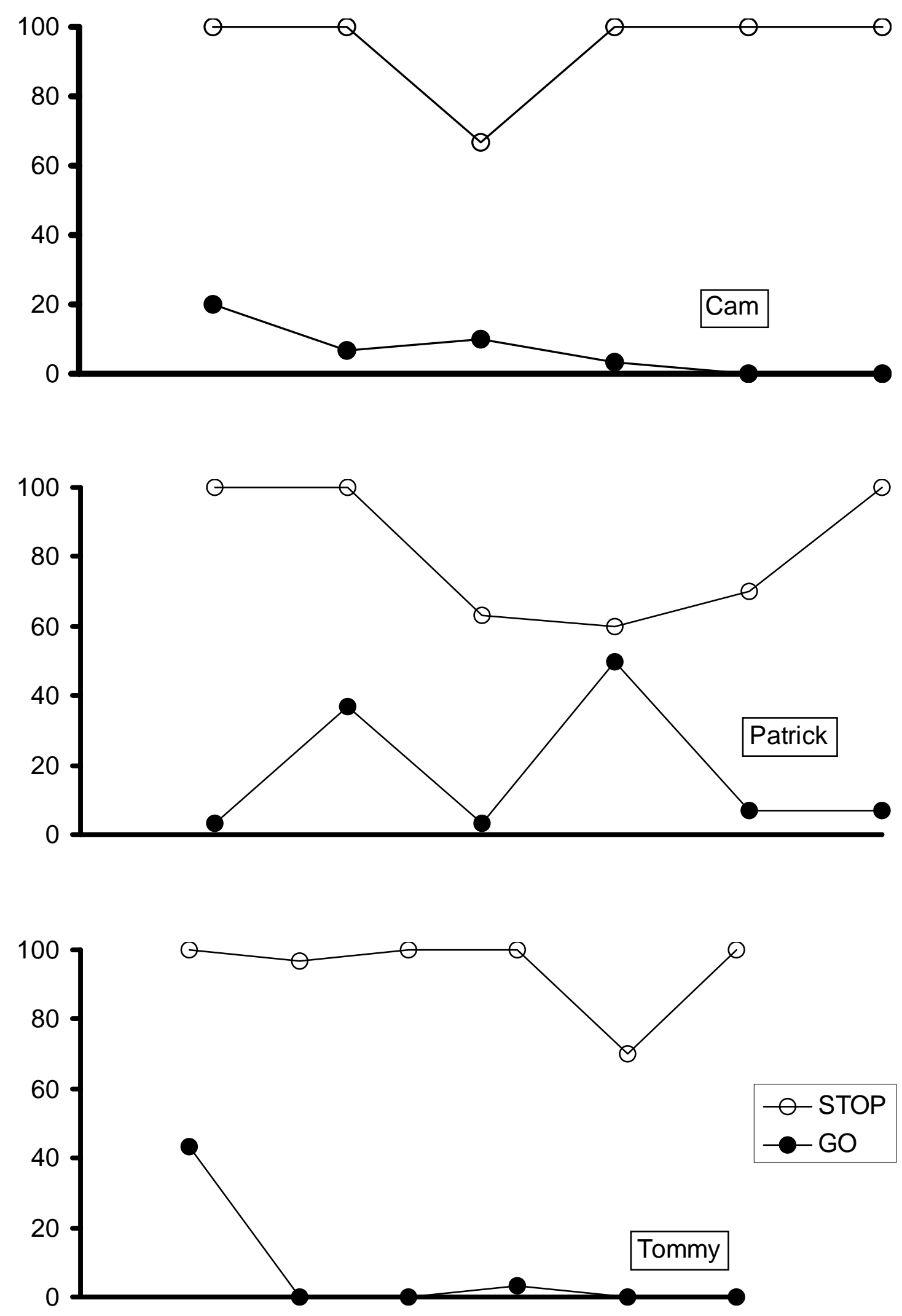


\section{EXPERIMENT 2}

Experiment 2 was conducted to determine if after responding was controlled by the $S^{\text {Dp }}$, participants would acquire a mand resulting in the stimulus correlated with nonpunishment. That is, Experiment 2 would determine if participants would request permission to have access to the $S^{\mathrm{D}}$, thus obtaining a level of control over the intervention. Furthermore, if such a mand was acquired and maintained, it would be determined if that mand would be brought under control by additional experimentercontrolled antecedent stimuli so that a practical intervention including both stimuluscontrol procedures and mand training might be developed.

Method

\section{Participants and Setting}

Participants and setting (unless noted otherwise) were identical to Experiment 1.

\section{Experimental Design}

The experimental design consisted of a multiple schedule embedded in an AB design, where "A" was DRA and "B" was stimulus-control training of mands. The final condition also had another multiple schedule embedded within to establish further experimental control.

Operational Definitions, Data Collection, and Interobserver Agreement

Participants’ manding was coded as a frequency measure. For Cam, manding was defined as removing an icon from the wall and placing it on a black square drawn on a piece of cardboard and releasing it. For Patrick, manding was defined as saying, “crayons, please.” For Tommy, manding was defined as taking an icon from a book and extending his arm such that the icon was six inches from the experimenter's hand. All other aspects regarding operational definitions and data collection were identical to Experiment 1.

With the exception of manding, all methods of interobserver agreement were identical to Experiment 1. Agreement for manding was calculated by dividing the number of agreements by the number of disagreements and multiplying by 100 . An agreement was scored when two coders scored a response separated by no more than one interval (allowing for approximately a six-second window for judgment of occurrence). The 
reason for employing such a liberal agreement measurement was that, observers often disagreed about the exact moment the mand began, due to the distance-criterion in the definition (e.g., holding the icon six inches from the experimenter). This discrepancy most likely occurred as one observer often collected data in vivo and the other often collected data from a videotape. All other operational definitions and aspects of data collection and interobserver agreement were identical to Experiment 1.

\section{Procedure}

All sessions were 10 min in length unless otherwise noted. Each condition had a minimum of 15 sessions unless otherwise noted. Stability was considered by examining the last six sessions (unless fewer sessions of data were collected; e.g., follow-up sessions) of stereotypical responding, manding, percent of session elapsed prior to first response (in sessions other than acquisition), and percent of session spent in each component. Stability criteria were identical to Experiment 1 (except for the final condition with Cam, which was terminated).

\section{Baseline}

Results obtained in Experiment 1 served as baseline for Experiment 2.

\section{Differential Reinforcement of an Alternative Response}

Acquisition. During mand training, the STOP stimulus was present until manding was prompted. Training was conducted using errorless backward chaining. Physical guidance was faded from full-physical prompts to partial-physical prompts, to gestural prompts, to no prompts based upon accuracy of each step across three trials. Prompting occurred continuously throughout the STOP components of the 10-min sessions until prompting was completely faded. Failure to emit the mand after approximately 30 s once prompt fading began resulted in returning to the previous level of prompting. In the presence of the GO stimulus, there were no programmed consequences for the occurrence of either targeted response (i.e., stereotypy or mand). In the presence of the STOP stimulus, following any prompted or unprompted mand, the GO stimulus was presented (for 20 s for Tommy; 1 min for Patrick; and initially 20 s for Cam, but 1 min after 3 sessions). Prompting continued in this manner throughout the 10-min session. Once prompt fading was initiated, stereotypy in the STOP component was followed by the 
punisher on an FR-1 schedule. The prompt hierarchy continued until manding occurred independently across at least two consecutive sessions across two days (with the next-tolast session ending in a minimum of three unprompted trials). Prompting was completely faded in two sessions for Tommy and six sessions for Cam. Repeated attempts were made to teach Patrick a mand resulting in the wristband, none of which were successful.

Evaluating the effects of training. Sessions were programmed to be $10 \mathrm{~min}$ in duration; however, if a mand occurred close to the end of the session (i.e., within $10 \mathrm{~s}$ of the end of the session), the session was extended so the GO component was a minimum of $10 \mathrm{~s}$ (as not to inadvertently punish manding). After prompts were faded, the STOP component remained in place until the occurrence of a mand. Following at least 15 sessions and stability in all dependent measures (as judged by visual inspection) in the last six sessions, an attempt was made to withdraw response-contingent delivery of the $\mathrm{S}^{\mathrm{P}}$. All other procedures remained the same, but the occurrence of the targeted stereotypy in the STOP stimulus was not differentially consequated. If rates of stereotypy increased across six consecutive sessions or if baseline levels of stereotypy occurred in any one session, punishment was reinstated.

As Patrick did not obtain a reliable, independent mand for the stimulus correlated with nonpunishment, his markers were withdrawn from him and he was taught to say “crayons, please,” which resulted in 1-min access to the markers. All other procedures were identical to those of the other participants. During this time, paper was available response independently and he acquired the vocal mand.

\section{Stimulus-Control Training: Mands}

It was predicted that a mand resulting in the stimulus correlated with nonpunishment (or, in Patrick’s case, the markers) would occur at such a high rate that participants would remain in the GO component almost continuously. As such, bringing manding under stimulus occurred next. For Patrick and Tommy, mands were brought under the control of two additional stimuli (and an attempt was made to do so for Cam). That is, in the presence of the STOP stimulus, there were two further components, stimuli correlated with the reinforcement of mands, and stimuli correlated with the extinction of mands. For Tommy, when the icon was on top of a container on the north side of the 
52

room, manding was reinforced. When the book was inside the container on the south side of the room and there was an " $\mathrm{X}$ " over the icon, manding was not reinforced. For Patrick, when the markers were in a clear container on his table, manding was reinforced and when they were in a nontransparent blue container on a shelf, manding was not reinforced. When manding was reinforced, the same contingencies were in place. When manding was not reinforced, Patrick did not have access to the markers, and thus occurrence of the targeted stereotypy was not possible. When manding was not reinforced for Tommy, there were no programmed consequences for stereotypy initially, although the $S^{\mathrm{P}}$ was reintroduced in one component later in the condition. These conditions were $2.5 \mathrm{~min}$ in duration and were alternated strictly within the 10 -min session.

Generalization Probes and Follow-Up Sessions

Generalization probes conducted with Tommy involved the same contingencies as the final phase of the experiment proper, but were conducted in Tommy’s bedroom at his residential facility immediately after the end of the experiment proper. Follow-up sessions were identical to the final phase of the experiment, and were conducted in the lab, but they were conducted one and three months after the end of the experiment with no practice, and no contact with the stimuli, the lab, or the experimenter in the meantime.

\section{Results}

Again, percent of intervals scored with a stereotypical response and manding were measured for each participant across each condition. The percent of the component that had elapsed prior to the first relevant response (manding in Experiment 2) also was measured during the training condition to further evaluate the extent to which stimulus control of mands was achieved. In this experiment, percent of total session spent in each component also was measured.

\section{Cam}

Results for Experiment 2 are listed in Table 3 and shown for Cam in Figures 8 and 9. Percent of intervals scored with a stereotypical response is shown in the top graph of Figure 8 and mands per min are shown the bottom graph of Figure 8. Percent of component elapsed prior to first (relevant) response is depicted in the top graph of Figure 
53

9 and percent of session spent in each component is shown in the bottom graph of Figure 9.

Baseline

Baseline was established during Experiment 1. See Figure 3 for the results of Experiment 1 for Cam.

Differential Reinforcement of an Alternative Response

Prior to beginning this condition, mand training was conducted, as described in the Method section. In this condition, then, the STOP component was in place until Cam independently manded. During initial sessions, the GO component was in place for $20 \mathrm{~s}$; however, as shown in the top graph of Figure 8, stereotypy occurred in only a small percentage of intervals in GO. Cam frequently exhibited long latencies to engage in a stereotypical response; this overall low occurrence of stereotypy probably was due to the number of component changes compared to previously. As a result, the duration of the GO component was increased to $1 \mathrm{~min}$, resulting in increases in stereotypy to levels observed in previous conditions. To evaluate whether responding would remain suppressed in STOP if the punishment procedure was withdrawn, beginning in Session 133, stereotypy in STOP was no longer followed by programmed consequences. Although an increase in stereotypy was observed initially, responding decreased to previous levels after several sessions, so punishment never was reintroduced during this condition.

As shown in the bottom graph of Figure 8, mands per min decreased to near zero in the first three sessions, suggesting that perhaps 20-s access to stimuli associated with nonpunishment of stereotypy was not reinforcing. When component duration was increased to $1 \mathrm{~min}$, (indicated on the graph by the 1'), manding increased and, in fact, continued on an increasing trend throughout this phase. Manding never occurred in the GO component. Because manding was increasing, percent of session spent in each component was examined as a secondary measure. It is directly related to rate of manding; however, its depiction helped to provide a strong rationale for why stimulus control of manding needed to be conducted. 


\section{4}

Next Page

Figure 8. The top graph depicts the percent of intervals scored with stereotypy during Experiment 2 for Cam. The bottom graph shows mands per min during Experiment 2 for Cam. Solid vertical lines represent condition changes. Dotted vertical lines indicate a change in the punishment contingency (sessions with the contingency present denoted by "SP," in all other conditions, the punisher was absent). The numbers indicate length of the GO components. The black arrows in the top graph indicate where retraining of manding was conducted for Cam. 
Figure 8.
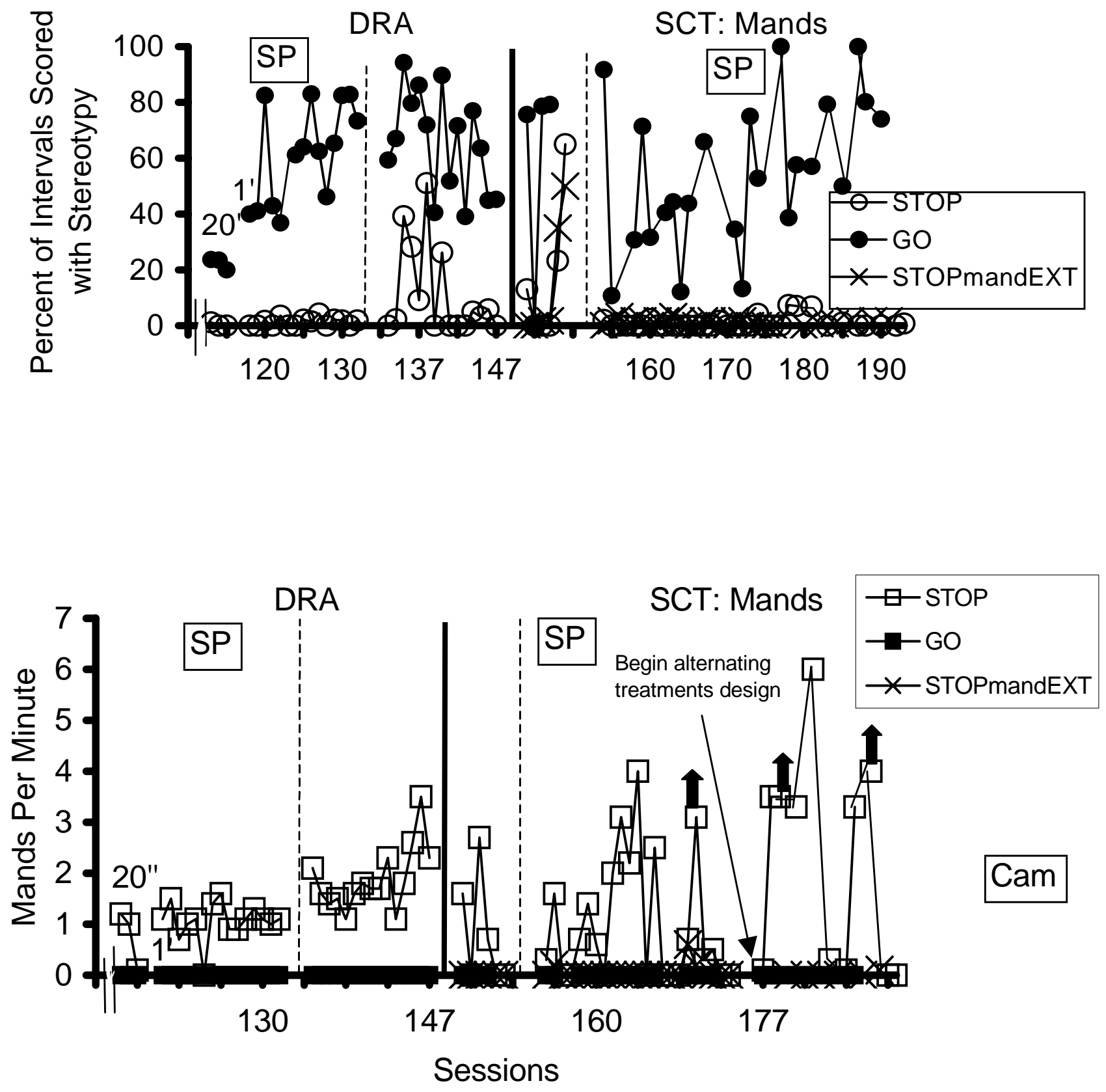
As shown in the bottom graph of Figure 9, as manding increased, the percent of time spent in the GO component necessarily increased as well. To illustrate, over the last 6 sessions of this phase, Cam spent an average of $67.1 \%$ of each session in the GO component. The percent of time in the GO component in the last six sessions was at a mean of $67.1 \%$. Such a high percent likely is not practical in the natural environment, and as such, manding was attempted to be brought under stimulus control.

\section{Stimulus-Control Training: Mands}

After stability was achieved with differential reinforcement of manding, the final condition, developing stimulus control over manding, was initiated. As in earlier conditions, there were no programmed consequences for manding in the GO component. In this phase, there were two STOP components; in one STOP component (indicated by the regular STOP icon), the mand was followed by 1 min access to the GO component, in the other STOP component (indicated by a red "X" on the icon), no programmed consequences followed the mand. Initially, there still were no programmed consequences for stereotypy in any STOP component, but due to an increase in stereotypy whether or not manding was reinforced (see top graph of Figure 8), the contingent delivery of the punisher was reinstated. Rapid suppression of stereotypy in both STOP components then was observed.

As in the previous condition, and as would be expected, the mand never occurred during the GO component and occurred only infrequently during the STOP component in which extinction was in place. More variability in the occurrence of manding was observed, as compared to the previous condition. In fact, there were several sessions in which the mand never occurred, suggesting possible carryover effects between the components whether manding was reinforced or not. Three times manding was prompted again and prompts were faded (indicated by the arrows in the bottom graph of Figure 8). Each time manding reached a rate similar to that observed in the previous condition, but each time was suppressed once stimulus-control training of manding began again.

In an attempt to eliminate carryover effects and develop stimulus control, the design was changed to an alternating-treatment design at Session 177. At this point, within-session component changes (with respect to manding) were eliminated. Instead 
Next Page

Figure 9. The top graph depicts the percent of depicts the percent of each component elapsed prior to the first occurrence of manding in the SCT: mands condition of Experiment 2 for Cam. Wherever more than one of any type of component occurs per session, the mean for that session is presented. The bottom graph depicts percent of each session spent in each component (i.e., STOP vs. GO) in Experiment 3 for Cam. The solid vertical line separates the conditions. The horizontal dotted line shows the point at which perfectly efficient manding would be graphed. 
Figure 9.
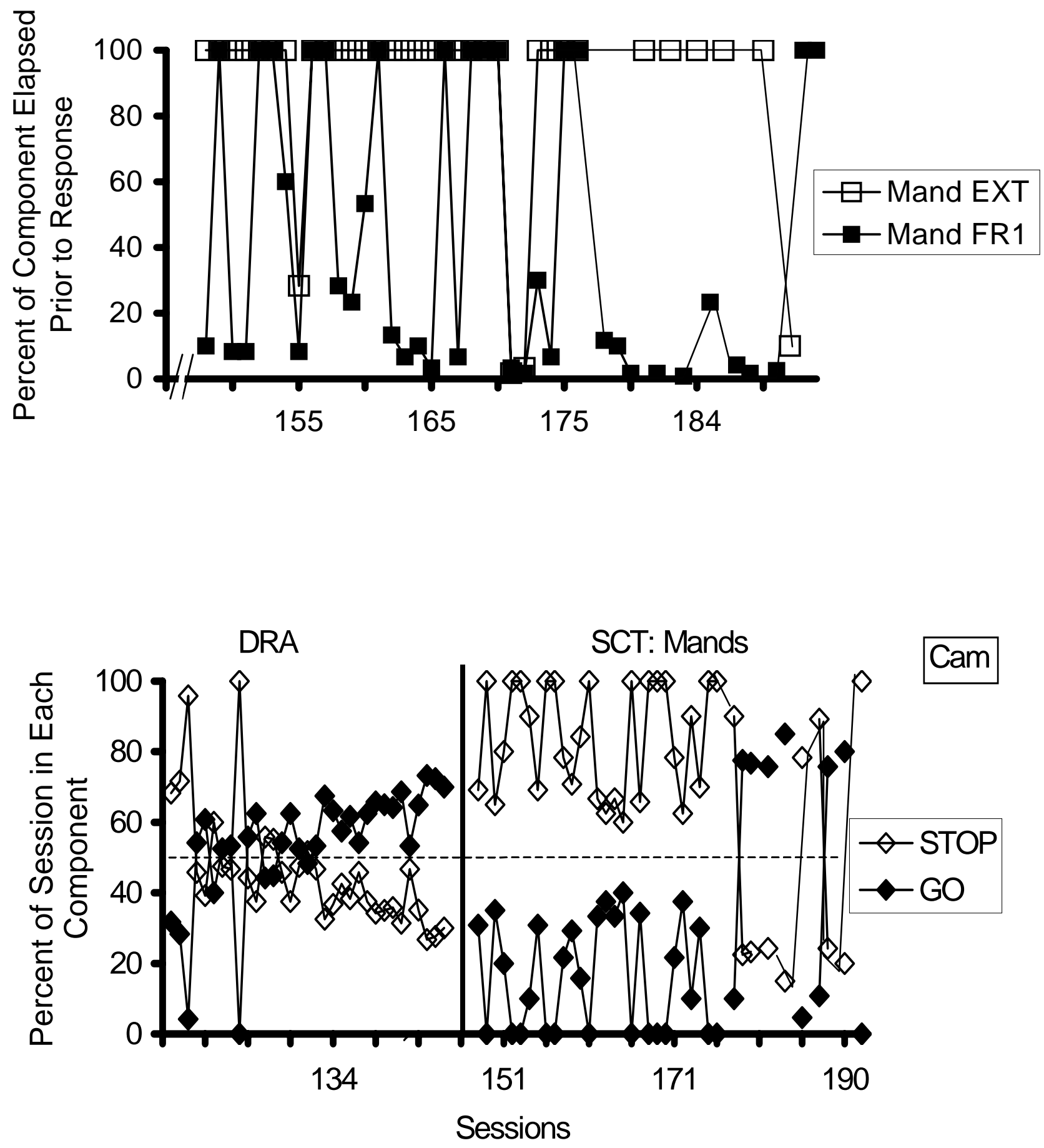
each component was in place for the entire session (i.e., each 10 min session consisted of either reinforcement or extinction of the mand; when manding was reinforced, withinsession component changes still were in place for access to the GO component).

Although increases in manding initially were observed in the STOP component where manding was reinforced, responding then was suppressed to zero in both components after a mand occurred (but was not reinforced) in the STOP extinction phase (Session 190).

Patrick

Results for Experiment 2 are listed in Table 3 and shown in Figures 10 and 11. Percent of intervals scored with a stereotypical response is shown in the top graph of Figure 10 and mands per min are shown in the bottom graph of Figure 10. Percent of component elapsed prior to first (relevant) response is depicted in the top graph of Figure 11 and percent of session spent in each component is shown in the bottom graph of Figure 11.

\section{Baseline}

Baseline was established during Experiment 1. See Figure 4 for the results of Experiment 1 for Patrick.

\section{Differential Reinforcement of an Alternative Response}

Unsuccessful mand training attempts. A mand resulting in access to the stimulus correlated with nonpunishment was not acquired independently. Three attempts were made to teach Patrick a new response that would be followed by access to the GO stimulus. Each attempt was terminated after nine sessions had elapsed without the occurrence of independent mands. In the initial attempt, which involved a picture icon, independent responding never occurred. To determine whether the failure to acquire independent responding was due to Patrick's inability to complete the response or to a lack of a salient reinforcer, icon exchange resulted in access to food. This mand was acquired in three sessions. An attempt then was made to transfer the reinforcer from food to the GO stimulus within session. That is, for one-half the session, the icon exchange resulted in access to food, and then the icon exchange resulted in access to the wristband 
after approximately 50\% of the session had elapsed. Independent manding again was suppressed once the contingency was changed.

As most of Patrick's mands in the natural environment were vocal, an attempt was made to teach a vocal mand (i.e., "Wristband, please). The mand was prompted vocally, and the prompts were faded, but independent manding never occurred. Finally, to minimize response effort, the wristband was placed under a clear plastic container and Patrick merely had to touch the container to gain access to the wristband. Again, once physical prompts were faded, no independent mands occurred. In each of these cases, the markers were present such that Patrick had access to the items required to engage in his targeted stereotypy. These three failed attempts at teaching a mand, together with the successful attempt to acquire a mand for food, demonstrated that Patrick could acquire a mand, but that a mand that resulted in access to the GO stimulus when the markers were present would not be maintained even with contingent $S^{\mathrm{P}}$ delivery for using these markers to engage in stereotypy.

Successful mand training. To complete mand training, the markers had to be withdrawn from Patrick and the mand, “crayons, please” was taught. This mand occurred independently after three sessions. Then, only three sessions with completely independent manding were conducted because the condition was not actually completed as planned, however, these three sessions are presented as they serve as a point of comparison once manding was brought under stimulus control.

As shown in the top graph of Figure 10, when Patrick was able to request markers, stereotypy in the GO component occurred at levels similar to those observed during previous conditions (there are no data in the STOP component because the targeted stereotypy could not occur). As shown in the bottom graph of Figure 10, mands in this condition were variable. Patrick spent almost three-quarters of each session in the GO component (see the bottom graph of Figure 11), as manding frequently occurred as soon as markers were removed. 
Next Page

Figure 10. The top graph depicts the percent of intervals scored with stereotypy during Experiment 2 for Patrick. The bottom graph shows mands per min during Experiment 2 for Patrick. Solid vertical lines represent condition changes. 
Figure 10.
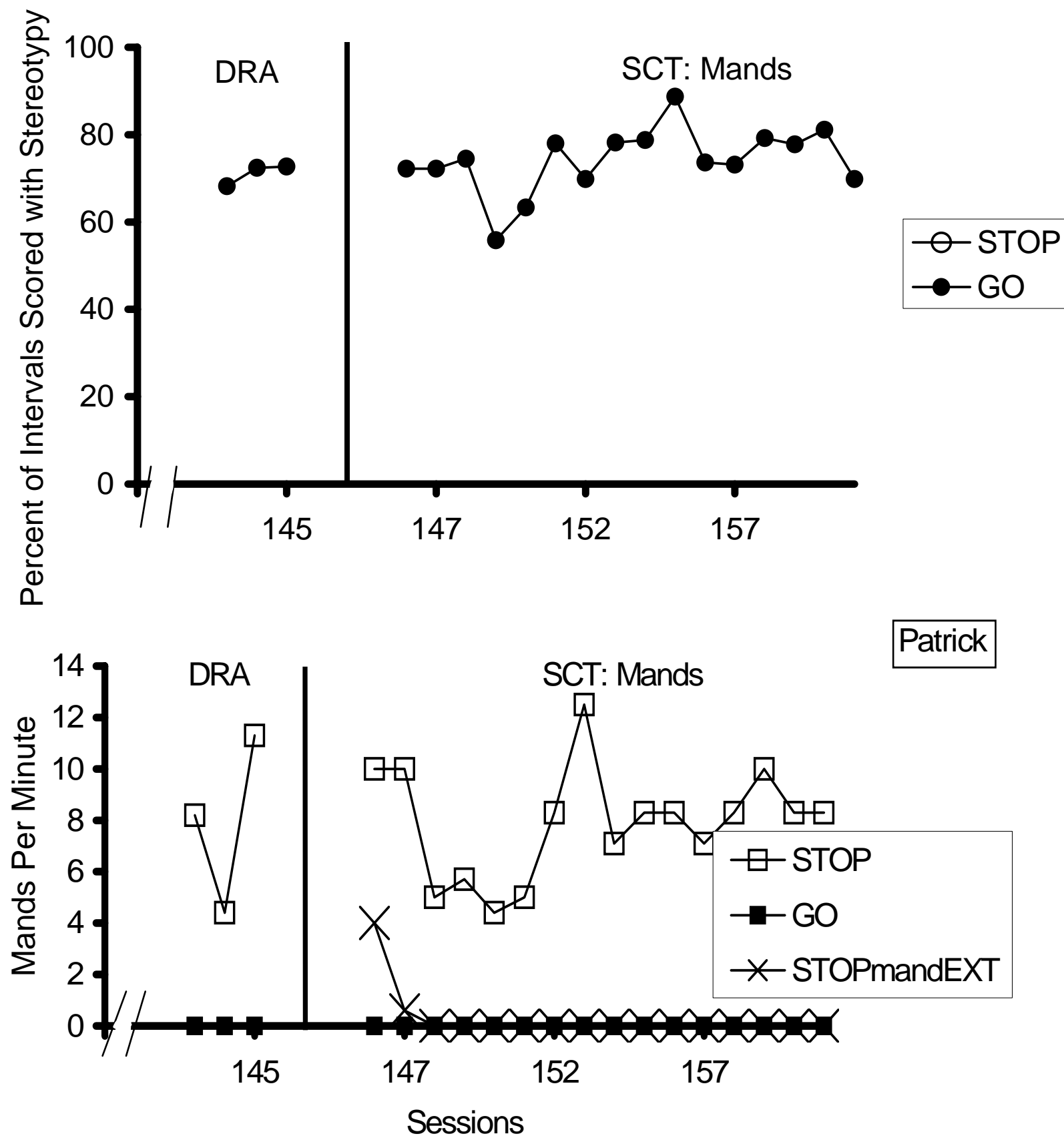


\section{Stimulus-Control Training: Mands}

In the STOP component of this condition, manding was reinforced on an FR-1 schedule when the markers were in one location and placed on extinction when located in another area of the room (STOP extinction component). Percent of intervals containing stereotypy are shown in the top graph of Figure 10. Stereotypical responding remained consistent in the GO component relative to previous conditions. Again, because the markers were not present during the STOP component, stereotypy could not occur.

The bottom graph of Figure 10 shows that the rate of manding in the STOP component remained consistent relative to the previous condition. In the STOP extinction component, manding rapidly was suppressed. As in the previous conditions, manding never occurred in the GO condition.

As depicted in the top graph of Figure 11, during initial sessions, manding occurred relatively early in both the STOP and STOP extinction components, but after three sessions, manding ceased to occur in the STOP extinction component (except for Session 155). Throughout this phase, manding occurred almost immediately in the component in which it was maintained by an FR1 schedule.

Finally, and perhaps most important to this condition, the bottom graph of Figure 11 shows that there was significantly less time spent in the GO component as the result of bringing manding under stimulus control. There also was little variability; this stability was due to the fact that, almost without fail, Patrick continued to mand immediately when the markers were withdrawn in the component in which manding was reinforced.

\section{Tommy}

Results for Experiment 2 are listed in Table 3 and shown in Figures 12 and 13. Percent of intervals scored with a stereotypical response is shown in the top graph of Figure 12 and mands per min are shown in the bottom graph of Figure 12. Percent of component elapsed prior to first (relevant) response is depicted in the top graph of Figure 13 and percent of session spent in each component is shown in the bottom graph of Figure 13. 
Next Page

Figure 10. The top graph depicts the percent of depicts the percent of each component elapsed prior to the first occurrence of manding in the SCT: mands condition of Experiment 2 for Patrick. Wherever more than one of any type of component occurs per session, the mean for that session is presented. The bottom graph depicts percent of each session spent in each component (i.e., STOP vs. GO) in Experiment 3 for Patrick. The solid vertical line separates the conditions. The horizontal dotted line shows the point at which perfectly efficient manding would be graphed. 
Figure 11.
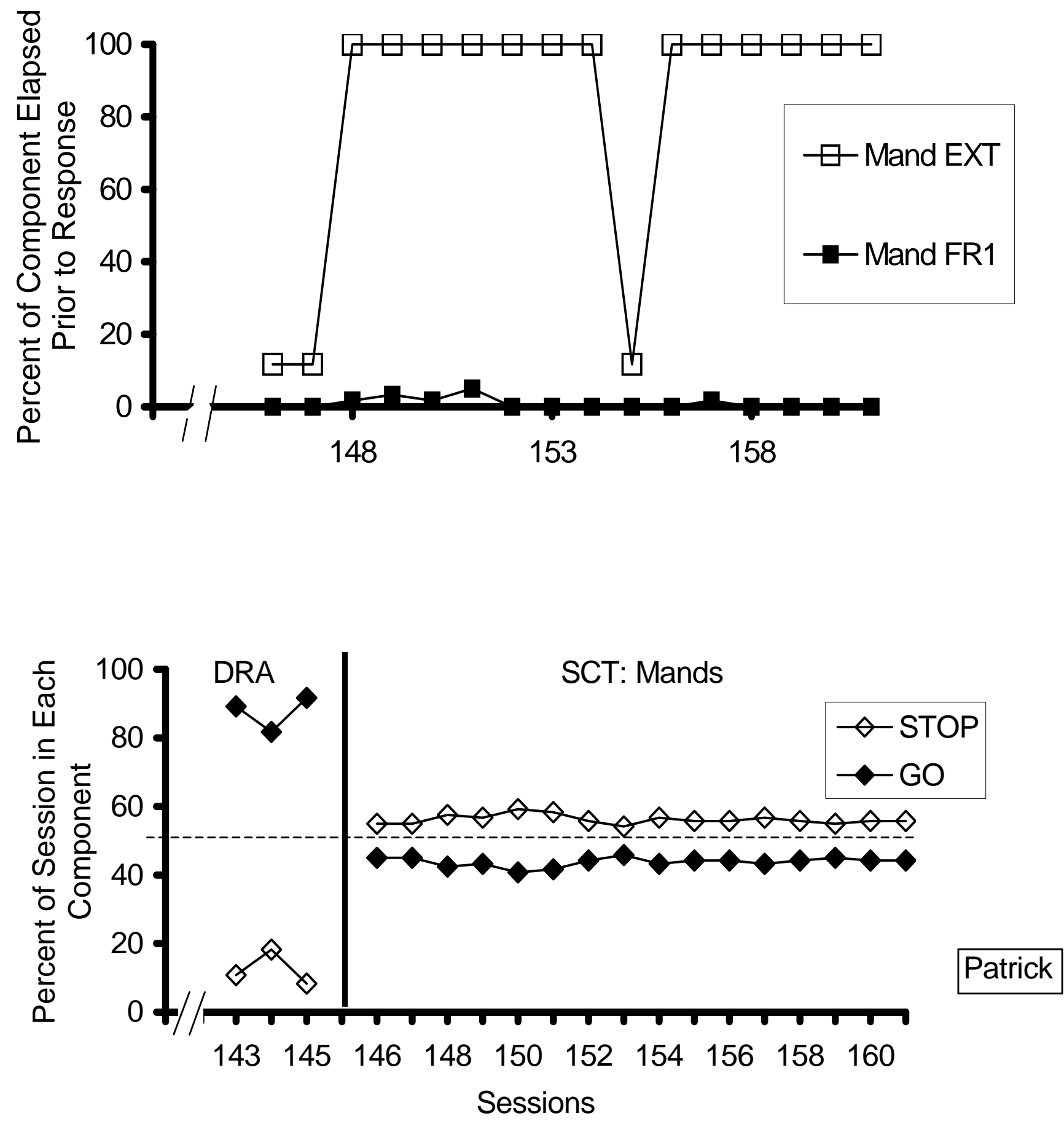


\section{Baseline}

Baseline was established during Experiment 1. See Figure 5 for the results of Experiment 1 for Tommy.

\section{Differential Reinforcement of an Alternative Response}

When Tommy was taught to emit a mand resulting in 20-s access to the GO component. Percent of intervals scored with a stereotypical response in the GO component remained consistent with previous conditions (see top graph of Figure 12). In the STOP component, stereotypy remained low, even when the $S^{\mathrm{P}}$ was withdrawn in Session 83. Therefore, the $S^{P}$ was removed for the remainder of this condition.

As shown in the bottom graph of Figure 12, after acquisition, manding occurred frequently in STOP but never in GO. As manding increased, amount of each session spent in GO necessarily increased as well (see bottom graph of Figure 13). As with the

other two participants, Tommy manded at much too high a rate to maintain in the natural environment, so manding was brought under stimulus control.

\section{Stimulus-Control Training: Mands}

In this condition, manding was brought under stimulus control. In this phase, there initially was no consequence for stereotypy in STOP as the punisher had been successfully withdrawn in the previous phase. As shown in the top graph of Figure 12, stereotypical responding in the GO component was slightly higher than in previous conditions. In the STOP component in which manding was reinforced, stereotypy occurred only infrequently. In the STOP component in which manding was extinguished (STOP extinction), indicated by a change in the appearance (and eventually a change in the location) of the icon, stereotypy gradually increased across six sessions, and the $\mathrm{S}^{\mathrm{P}}$ contingent upon stereotypy was introduced in this component. Thereafter, stereotypy decreased in the STOP extinction component.

As shown in the bottom graph of Figure 12, when manding continued to be reinforced continuously, rate of manding was higher than it had been in the previous condition. In the component in which manding was extinguished, manding originally occurred once in each session, at the beginning of the session. To attempt to gain control by the experimenter-arranged antecedent stimulus and not control by contact with the 
Next Page

Figure 12. The top graph depicts the percent of intervals scored with stereotypy during Experiment 2 for Tommy. The bottom graph shows mands per min during Experiment 2 for Tommy. Solid vertical lines represent condition changes. Dotted vertical lines indicate a change in the punishment contingency (sessions with the contingency present denoted by “SP,” and/or “*” in all other conditions, the punisher was absent). 
Figure 12.
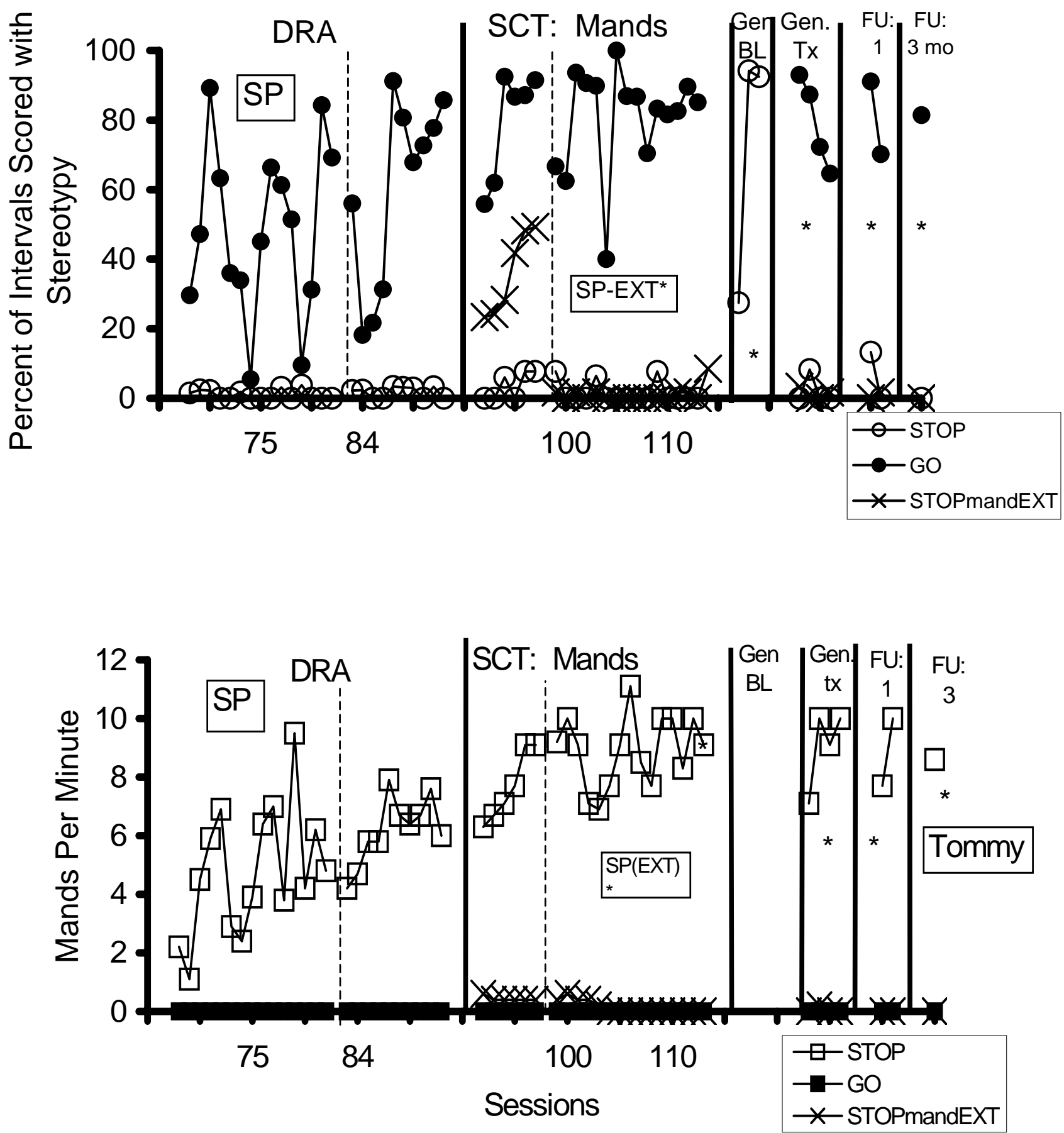
contingency (i.e., extinction), the location of the icon was moved. Tommy manded once in the beginning of the session in which the location was moved and then he never manded in this extinction component again. Manding never occurred in the GO condition.

As shown in the top graph of Figure 13, initially, manding occurred early in both STOP components, but, once the location of the icon was moved, manding only occurred one time in the STOP extinction component. Manding always almost immediately occurred in the component in which manding was reinforced continuously.

The bottom graph of Figure 13 shows that there was significantly less time spent in the GO component as the result of bringing manding under stimulus control. There was little variability in this phase, again, because Tommy manded almost immediately after the wristband was withdrawn in the condition where manding was reinforced. Generalization and Follow-Up Sessions

Due to the rapidity with which Tommy progressed through the study, time allowed for generalization and follow-up probes. Immediately following the completion of the experiment proper, baseline data were collected at Tommy's residential cottage. Stimuli for manding were not present, and the experimenter did not interact with Tommy (see the top graph of Figure 12). Although low levels of stereotypy were observed in the first session (he fell asleep), in subsequent sessions stereotypy occurred at levels similar to those observed in earlier conditions of the experiment. Following baseline, the contingencies were as they had been at the end of the experiment proper; Tommy's stereotypical responding (top graph of Figure 12) and manding (bottom graph of Figure 12) were similar to those observed in that last condition. Follow-up sessions in the lab were conducted at one month and three months, and patterns of responding were similar to those observed during the experiment.

\section{Discussion}

Each participant acquired a mand that resulted in access to conditions where stereotypy would be unpunished. Cam and Tommy manded using icon exchange, and Patrick had a vocal mand. Only two of the three participants (i.e., Cam and Tommy) learned a mand resulting in contingent access to the $S^{\mathrm{D}}(\mathrm{GO})$. Patrick instead learned a 
Next Page

Figure 13. The top graph depicts the percent of depicts the percent of each component elapsed prior to the first occurrence of manding in the SCT: mands condition of Experiment 2 for Tommy. Wherever more than one of any type of component occurs per session, the mean for that session is presented. The bottom graph depicts percent of each session spent in each component (i.e., STOP vs. GO) in Experiment 3 for Tommy. The solid vertical line separates the conditions. The horizontal dotted line shows the point at which perfectly efficient manding would be graphed. 
Figure 13.
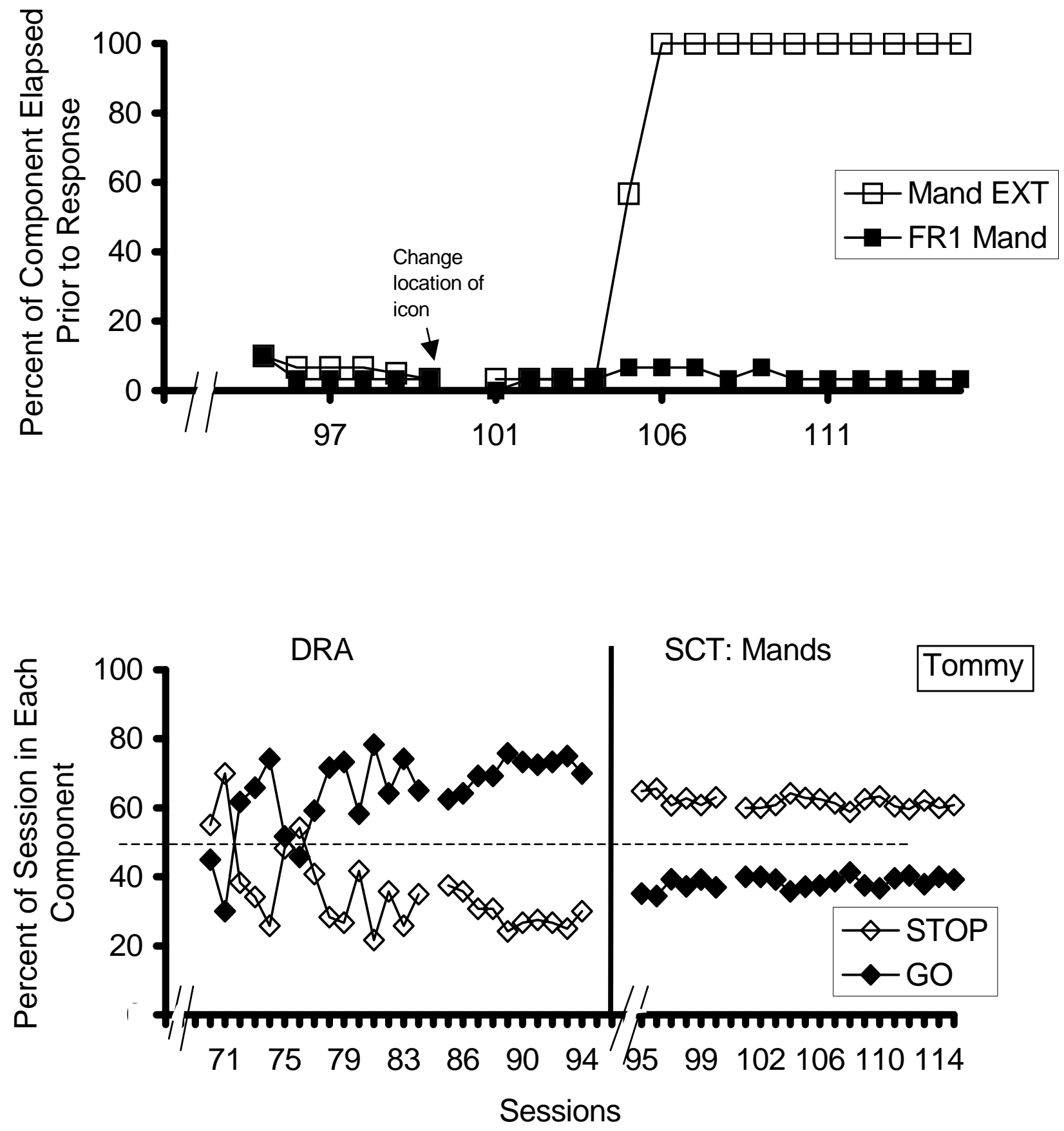
mand resulting in access to items necessary to engage in stereotypy (i.e, markers). For this reason, Patrick no longer could engage in stereotypy in the STOP component. Stereotypy and manding during the last six stable sessions of each condition of this experiment are presented for each participant in Figures 14 and 15, respectively.

Furthermore, for Patrick and Tommy, manding also was brought under stimulus control. Specifically, under certain idiosyncratic experimenter-arranged stimulus conditions, manding was reinforced, and under other conditions, it was extinguished. Selection of the stimuli signaling the different components depended on the participants' previous exposure to Experiment 1 as well as their physical limitations (e.g., Tommy’s vision and hearing limitations). During the last six sessions, manding was determined to be controlled by these experimenter-arranged antecedent conditions, and not by the occurrence of the consequences (responding never occurred in the extinction component during the final six sessions). Although Cam's manding was not brought under stimulus control, the condition was terminated.

\section{Chapter 3 - Conclusions}

\section{GENERAL DISCUSSION}

In analyzing each dependent variable, several findings were observed. These findings are discussed as they relate to the experimental questions addressed in the study. First, differential stereotypical responding and the source of such stimulus control are examined. Then, the acquisition of an appropriate alternative is discussed. Next, the applied value of the procedures is analyzed and practical interventions are discussed. Finally, future directions for research are proposed.

Differential Stereotypy and Identifying the Source of Stimulus Control

Following introduction of the punishment procedure, stereotypy was brought under stimulus control with each participant. Although stereotypical responding was not suppressed completely in the STOP component with any participant, clinically significant differences across components were observed. 
Next Page

Figure 14. Percent of intervals scored with stereotypy for the last six stable sessions of the training condition (i.e., stimulus control of mands) of Experiment 2. Results in the top, middle, and bottom graphs are for Cam, Patrick, and Tommy, respectively. 
Figure 14.

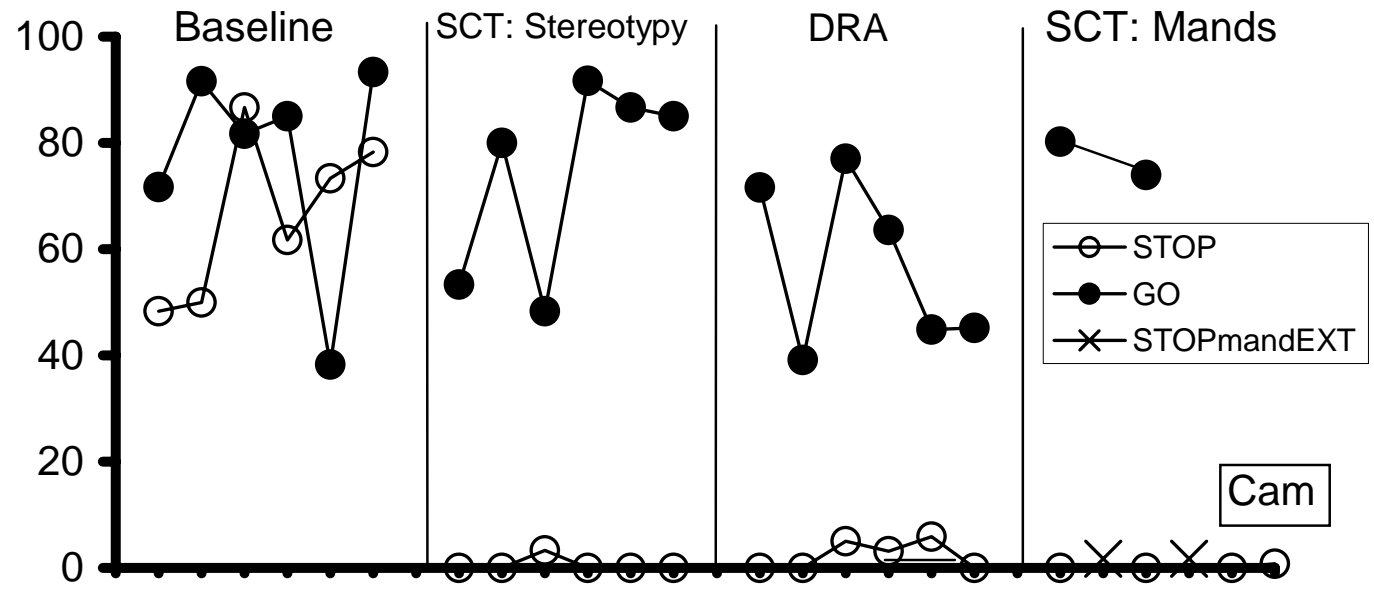

0
0
0
0
0
0
0
0
0
0
0
0
0
0
0
0
0
0

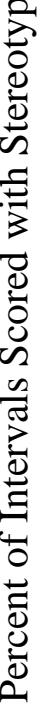
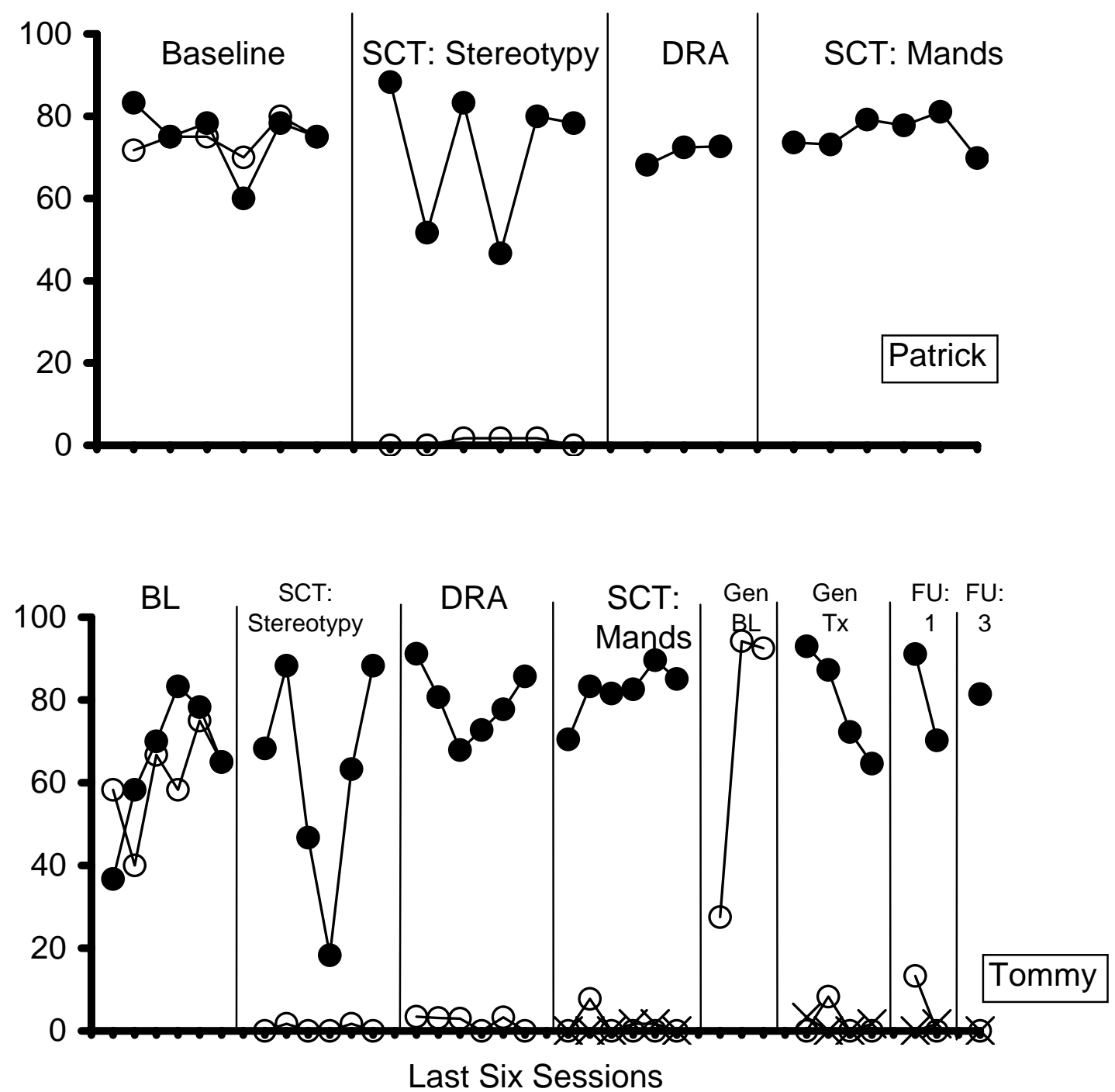
Next Page

Figure 15. Mands per min for the last six stable sessions of the training condition (i.e., stimulus control of mands) of Experiment 2. Results in the top, middle, and bottom graphs are for Cam, Patrick, and Tommy, respectively. Note the different scales on the yaxis. 
Figure 15.
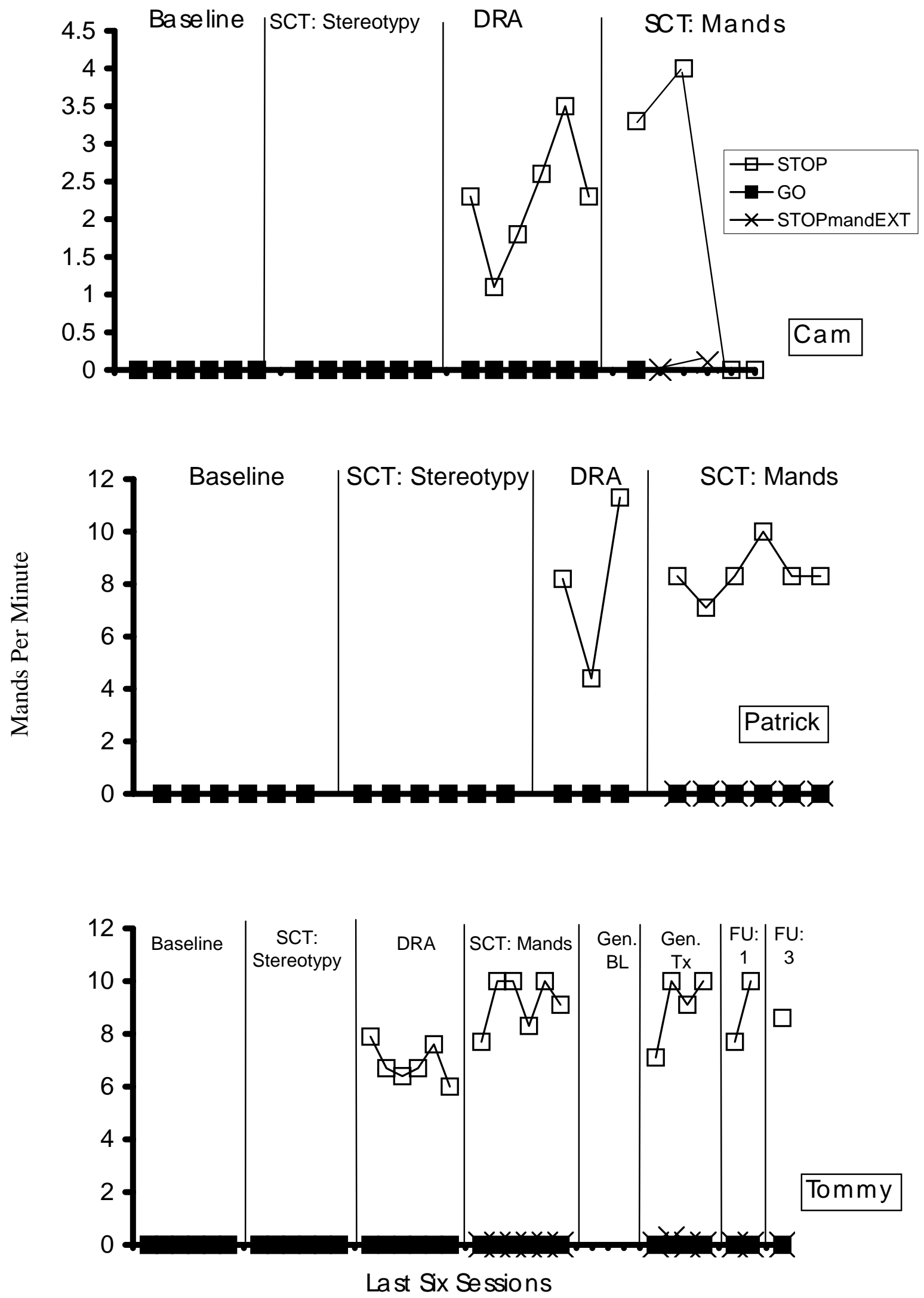
Two features of the results obtained with Patrick require further comment: minimal responding in the GO component when component length was 1 min and suppressed responding in many GO components when they followed STOP components. First, prior to changing the 5-min components to 2.5-min components, 1-min components (and a reversal to 5-min components) were employed. Stereotypy decreased markedly in the GO component when the components were $1 \mathrm{~min}$ in duration. This decline presumably occurred because of relatively long latencies to respond in each component. The specific topography of Patrick’s stereotypy required several preparatory responses (e.g., opening notebook, uncapping markers) that consumed a significant amount of time in the GO component; perhaps the remaining time spent engaging in stereotypy was not sufficient to reinforce these preparatory responses. With reference to the second feature, although Patrick’s stereotypy remained relatively low in the STOP component, there were occasions in which responding was low in the GO component as well. In many of these cases, the STOP component preceded the GO component and it was observed anecdotally that in some of these cases, especially earlier in training, Patrick was engaged in some other activity (e.g., cleaning up), which continued when the components changed. This observation is not important from a practical standpoint, as the goal of having Patrick engage in little stereotypy in the STOP component was achieved, however, it is relevant when examining the source of stimulus control.

To evaluate the source of stimulus control (i.e., control by $S^{\mathrm{P}}$ or $\mathrm{S}^{\mathrm{Dp}}$ ) of stereotypy, response latencies in each training condition were examined by measuring the percent of each component elapsed prior to the first response. If responding were controlled by the consequences alone, latency to respond in each of the components (STOP vs. GO) would be undifferentiated. If responding instead were controlled by the $S^{\text {Dp }}$ (due to a history of differential punishment), then relatively longer latencies should occur in the STOP component, in which stereotypy was punished. Differential latencies were observed with all participants, but were obtained most rapidly with Cam and Tommy, observed after twenty sessions of training with Cam and six sessions with Tommy. Patrick did not exhibit differential latencies during either 5-min or 1-min components. But, by the last six sessions of 2.5-min components, there was no overlap in 
latencies in the STOP and GO components. Also, any stereotypy exhibited by Patrick in STOP occurred in the last $50 \%$ of the session, whereas stereotypy in the GO component often occurred within the first $50 \%$ of the session. Thus, the combined analyses of response occurrence and relative response latency demonstrated antecedent stimulus control of stereotypy using punishment. The next issue was to determine if a mand for the stimulus correlated with nonpunishment of stereotypy could be acquired.

Acquisition and Maintenance of an Appropriate Response

Only Cam and Tommy acquired and maintained a mand for a stimulus correlated with nonpunishment; Patrick instead learned a mand correlated with delivery of stimuli necessary for stereotypy to occur (i.e., markers). For Cam and Tommy, manding was maintained even after the $S^{P}$ was withdrawn. There are at least three possibilities for Patrick's failure to maintain the mand for the stimulus correlated with nonpunishment of stereotypy. First, it is possible that stereotypy did not serve as a reinforcer. This possibility is not likely, however, as Patrick later learned a mand for markers (which he used only to engage in stereotypy). Second, it is possible that there never was control over the relevant variables in that responding was not under the control of the presence or absence of the wristband. Third, it is possible that the punisher was not sufficient to suppress responding completely in the STOP component, thus responding persisted, and the mand never was acquired. In this case, as stereotypy continued to occur, manding was neither efficient nor necessary. This interpretation seems most likely and is supported by anecdotal data. Specifically, in the STOP component; Patrick occasionally emitted phrases such as, "How about just one time?” Though such vocalizations were not consistently observed and only are anecdotal evidence, they support the contention, along with the differential latencies, that the punisher was not sufficient. This hypothesis could have been tested by identifying and testing a more effective punisher but given the benign nature of the stereotypy, as well as the ease with which materials needed for the response to occur could be manipulated, such a decision was not warranted. Instead, the markers were withdrawn, and a mand resulting in marker access was taught.

Each participant initially manded at such a high rate that it was reasonable to attempt to bring manding under stimulus control. Stimulus control of manding developed 
for two of three participants, Patrick and Tommy. For Patrick, antecedent control developed within three sessions and for Tommy, antecedent control of manding developed after only one mand occurred in the extinction component (i.e., once the placement of the icon had been changed). The analysis including percent of session elapsed prior to the first mand demonstrated that responding at least was partly under the control of the antecedent conditions and not merely the consequent conditions.

Finally, for Cam, attempts to bring manding under stimulus control were unsuccessful. This difficulty makes sense given that the conditions under which responding came under stimulus control for each participant were idiosyncratic. For example, as was mentioned above, both Cam and Patrick required several attempts to bring stereotypy under stimulus control in that the environmental conditions and punishers delivered were changed in pretraining attempts. For Cam in this final condition, then, it seemed as though the stimulus conditions that would be effective for Cam might again only be found through trial and error. Because the experimental questions already had been addressed and a practical intervention (i.e., suppression of stereotypy in the presence of another person) had been developed, further evaluation with Cam was not warranted. In these cases where it was difficult to determine stimuli that would be effective in bringing responding under stimulus control, the reasons for this challenge remain undetermined. These reasons, however, might be related to attention. For example, as has been indicated previously, McIlvane and Dube (2003) note that stimuli often are complex in that they have multiple aspects to attend to. Thus, it is unclear what the present participants were attending to; as such, trial-and-error methods were employed to find effective stimuli.

In conclusion, then, with regard to stimulus control and the question of the source of the control, Experiment 1 demonstrated that stereotypy could be controlled by the $S^{\text {Dp }}$ and not merely the $S^{\mathrm{D}}$, and in Experiment 2, manding finally was controlled differentially by the onset of a stimulus correlated with extinction. Thus, differential latencies across components occurring both with stereotypy and manding demonstrate that control by experimenter-arranged antecedent stimuli can develop both with punishment (i.e., stereotypy) and with extinction (i.e., mands). As opposed to some previous research, the 
procedures and analyses employed within clarify the roles of the antecedent and consequent stimuli in the control of behavior.

Applied Value: Stimulus Control and Manding to Develop Interventions

In addition to the value obtained by understanding the source of stimulus control in this study, useful interventions were developed for the sensory-maintained responding of each participant. The stereotypies were brought under the control of practical stimuli in an intervention that could be employed in the natural environment. Each participant also was taught a more appropriate manner of obtaining an environment in which stereotypy could go unpunished. Or, more colloquially, participants discriminated where they were not permitted to engage in inappropriate behavior and maintained a request for permission to engage in the stereotypy (even though two of the three could engage in the stereotypy without that permission).

An example of the usefulness of the aforementioned enterprise might assist in emphasizing the importance of stimulus-control and mand training. Consider the parents of a child with autism who have reported that if their son wants to engage in hand flapping, that at least he do so only in the privacy of his bedroom, not in the family room when the family is gathered around watching television. These parents then teach their son that when in the family room, if he wants to flap his hands, then he needs to ask his parents to go to his bedroom to do so. However, if he hand flaps in the family room, an aversive consequence will be delivered. It is likely that this child would have learned that if he wants to hand flap continuously, he merely has to ask to go to his room continuously. His parents report that they do not mind if their son usually spends a lot of time in his room, as long as he is appropriate when he is in the family room. The exception to this standard occurs when they have guests visiting with the family in the family room - they want their son to be there also, and still behaving appropriately. If an effective intervention employing differential punishment of hand flapping, mand training, and differential reinforcement of manding is developed, the child's parents likely are to be content with the results. The child will stop hand flapping in the family room altogether, and will ask to go to his room and hand flap only when there is no company. This example illustrates the present intervention. 
81

Practicality of the Stimuli and Utility of the Interventions

For all participants in the present investigation, stereotypy was brought under the control of stimuli readily available and relatively unobtrusive in the natural environment (i.e., “alone” for Cam, wristbands for Patrick and Tommy). In addition to the practical nature of the stimuli used to bring stereotypy under environmental control, the punishers employed for Cam and Tommy were very inconspicuous; even if the punishment delivery is observed, it likely is not socially stigmatizing. A simple response-interruption procedure was employed, and was implemented very rarely; responding mostly was suppressed when the $S^{\mathrm{Dp}}$ was delivered. For Patrick, however, stereotypy was not suppressed completely and the $S^{\mathrm{P}}$ likely would never have been withdrawn successfully for any length of time. Still, stimulus-control training was successful to some degree and a practical intervention involving DRA was employed successfully (discussed below).

\section{Manding and Stimulus Control}

The study also demonstrated that individuals with severe and profound mental retardation will learn a mand for permission to engage in stereotypy (giving them some control over their own environment). Cam acquired a mand for the stimulus correlated with nonpunishment; however, he manded at such a high rate that he spent most of his time in the GO component, an intervention that likely would not be practical for the natural environment. Thus, merely the stimulus-control procedure alone would need to be employed, or, manding eventually would have to be brought under some form of stimulus control. It is likely that Cam's manding could be brought under stimulus control. The conditions under which Cam's stereotypy came under stimulus control were very specific and determined only after three failed attempts. Therefore, the environmental conditions under which Cam's manding would be brought under stimulus control ought to be studied.

Patrick’s stimulus-control procedure involving stereotypy likely would not be successful in the natural environment and thus was abandoned in favor of the DRA procedure alone. The topography of his stereotypy, and the materials needed, allowed for a simple intervention involving withdrawing the markers and then teaching a mand resulting in the markers. Finally, that mand was brought under stimulus control, such that 
82

Patrick, like Tommy, only manded under environmental conditions where there was a history of that mand being reinforced.

Tommy manded in the STOP component whenever the stimulus conditions signaled that manding would be reinforced. He manded before engaging in stereotypy, despite a long history of engaging in the stereotypy, and he rarely engaged in stereotypy in the STOP condition when manding was available, even when the $S^{\mathrm{P}}$ was withdrawn. When manding was not available, the $S^{\mathrm{P}}$ had to be delivered contingent upon stereotypy. This intervention continued to be effective one and three months after the experiment and generalized to his residential cottage.

\section{The Necessity for Alternative Sources of Stimulation}

Piazza et al. (1996) achieved a practical stimulus-control intervention with one participant. However, that participant also had response-independent availability of food, and the final condition was terminated after only twelve 10-min sessions. Patrick and Tommy had continuous access to toys, but only Patrick ever engaged in toy play, and he did not do so consistently. Cam did not have access to any toys or preferred items. Still, for each participant, stimulus control developed despite rarely interacting with alternative stimuli. Also, as emphasized in Table 2, stereotypy occurred mainly in the GO component for each participant for a minimum of 80 sessions (and in Cam's case, over 150 sessions), regardless of interventions for manding and (in Tommy’s case) despite a generalized environment and several months without experimental exposure.

As a result, a practical combined intervention employing stimulus-control training and the differential reinforcement of manding was successful in controlling sensorymaintained stereotypies. The use of what generally are considered to be mild aversive stimuli was successful in reducing responding of adults that reportedly had engaged in stereotypy for over half of their waking hours for many years. While the delivery of this punisher only was withdrawn successfully with one participant (Tommy), control by the $S^{\text {Dp }}$ developed with all participants, dramatically reducing the frequency with which the punisher was delivered. Finally, each participant learned a mand that allowed them access to environmental conditions under which they could engage in unpunished stereotypy. 
83

Employing interventions combining differential punishment and DRA will allow other participants exhibiting similar topographies of behavior with presumably the same function to continue to have access to a reinforcing, but occasionally inappropriate, event. Allowing participants to have conditional access to unpunished socially inappropriate behavior is not a new notion (e.g., Charlop et al., 1990). By extending a stimulus-control intervention to also include personal control (here, manding) under some circumstances allows individuals with disabilities to choose when to have access to reinforcers. It already has been stated that individuals prefer to control some aspects of their intervention (e.g., Hanley et al., 1997). One movement within behavior analysis to allow individuals more control is person-centered planning (e.g., Kincaid \& Fox, 2002). While programs such as person-centered planning generally discourage the use of punishing stimuli (e.g., Horner et al, 1990), the infrequent delivery of an inconspicuous punisher, paired with the conditional access to a reinforcing event (i.e., stereotypy), hardly can be considered "undignified” or "disrespectful”- a primary concern of proponents of nonaversive techniques. The stimuli and punishers employed here may not be effective across all individuals. Nevertheless, the combination of control by the experimenter (i.e., stimulus control of stereotypy) which allows for prevention of stereotypy in inappropriate situations, and control by the individual (i.e., DRA), serves to balance the needs for both personal freedom and social appropriateness by individuals with developmental disabilities.

\section{Future Directions}

This experiment examined the use of stimulus control, punishment, and differential reinforcement of an alternative response to control sensory-maintained stereotypies in adults with mental retardation. The findings provoke future research possibilities, both basic and applied. Both basic and applied researchers may examine further the issue of choice; for example, preference for interventions might be examined further. Both interventions using stimulus control and differential reinforcement of manding here were conducted — an additional step would involve determining preference for the experimenter-controlled versus the participant-controlled treatment. Previous researchers (e.g., Patel et al., 2004; Woods et al., 1983) have observed an increase in 
responding in one component, when stereotypy-contingent punishment occurs in the other component. This phenomenon is similar to the notion of punishment contrast (e.g., Crosbie, Williams, Lattal, Anderson, \& Brown, 1997). Punishment contrast is not a wellunderstood phenomenon. While some differences in the aforementioned studies distinguish the results from traditional punishment contrast, its obvious applied value (in addition to the failure to observe such contrast in the present study) makes the study of punishment contrast warranted.

Finally, the possibility of applied systematic replications emerges from these results that have implications for further interventions. First, future research should examine the extent to which these findings would be replicated with other populations, other topographies and functions of behavior, and in more natural settings. The conditions under which stimulus control developed with each of these participants were idiosyncratic. To determine if such an intervention is practical in the natural environment, applied research should examine systematically whether stimulus control over responding could be achieved and maintained in more natural environments, such as responding in one manner on the playground and in another manner indoors. Applied researchers also should examine whether responding can be brought under the control of natural and obviously relevant stimuli, and whether individuals would learn to request situations where such behavior would be appropriate. Finally, one other aspect of the natural environment remains unexamined. Specifically, rarely is treatment integrity in the natural environment "perfect." That is, in this and other studies, responding during the presentation of an environmental stimulus is correlated perfectly with a consequence, whereas in natural settings, this perfect correlation often does not occur. It would be noteworthy to determine the extent to which some antecedents and consequences must be correlated for stimulus control to develop. As such, a number of interventions utilizing stimulus control and mand training might emerge from future research.

\section{Conclusion: Impact of the Investigation of Stereotypy}

Stereotypy is a significant problem among individuals with developmental disabilities and, as such, an important consideration for applied behavior analysts. Developing interventions for responses that may be sensory maintained, or automatically 
reinforcing, poses unique obstacles in the development of function-based treatment options. Ignoring the function of the problem behavior, or failing to encourage appropriate means of obtaining the reinforcer, may increase the likelihood of treatment failure. Treatment failure then may result in the appeal to unnecessary or ineffective treatments. Particularly among institutionalized individuals, pharmacological treatments, for example, frequently are used to decrease problem behaviors such as stereotypy. Oftentimes multiple medications are prescribed to these individuals, despite the fact that their effects have not been investigated sufficiently in the populations in which they are used (e.g., Williams \& Saunders, 1997). As such, behavioral treatments must continue to be relied upon as a primary intervention, wherever possible.

Many individuals with developmental disabilities exhibit stereotypy in such a manner or at such a rate that it interferes with appropriate skill development (including social interaction) Accordingly, measures are taken to control, reduce, or eliminate such stereotypy. The process of developing new interventions, modifying existing procedures, and combining treatments to decrease the rate of problem behaviors, while teaching and maintaining appropriate alternatives, must continue to be a focus of researchers. By doing so, the quality of life of individuals with developmental disabilities is likely to be improved. 
References

Azrin, N. H., \& Holz, W. C. (1966). Punishment. In W. K. Honig (Ed.). Operant Behavior: Areas of Research and Application. Englewood Cliffs, NJ: PrenticeHall, Inc.

Baer, D. M., Wolf, M. M., \& Risley, T. R. (1968). Some current dimensions of applied behavior analysis. Journal of Applied Behavior Analysis, 1, 91-97.

Bodfish, J. W., \& Lewis M. H. (2002). Self-injury and comorbid behaviors in developmental, neurological, psychiatric, and genetic disorders. In S. R. Schroeder, M.L. Oster-Granite, \& T. Thompson (Eds.). Self-Injurious Behavior. Washington, D.C.: American Psychological Association.

Carr, E. G., \& Durand, V. M. (1985). Reducing behavior problems through functional communication training. Journal of Applied Behavior Analysis, 18, 111-126.

Charlop, M. H., Kurtz, P. F., \& Casey, F. G. (1990). Using aberrant behaviors as reinforcers for autistic children. Journal of Applied Behavior Analysis, 23, 163181.

Cooper, J. O., Heron, T. E., \& Heward, W. L. (1987). Applied behavior analysis. Upper Saddle River, NJ: Prentice-Hall, Inc.

Crosbie, J. Williams, A. M. Lattal, K. A. Anderson, M. M. \& Brown, S. M. (1997). Schedule interactions involving punishment with pigeons and humans. Journal of the Experimental Analysis of Behavior, 68, 161-175.

Denney, J., \& Neuringer, A. (1998). Behavioral variability is controlled by discriminative stimuli. Animal Learning and Behavior, 26, 154-162.

Dinsmoor, J. A. (1995a). Stimulus control: Part I. The Behavior Analyst, 18, 51-68.

Dinsmoor, J. A. (1995b). Stimulus control: Part II. The Behavior Analyst, 18, 253-269.

Durand, V. M., \& Carr, E. G. (1991). Functional communication training to reduce challenging behavior: Maintenance and application in new settings. Journal of Applied Behavior Analysis, 24, 251-264.

Durand, V. M., \& Carr, E. G. (1992). An analysis of maintenance following functional communication training. Journal of Applied Behavior Analysis, 25, 777-794. 
Fisher, W. W., Kuhn, D. E., \& Thompson, R. H. (1998). Establishing discriminative control of responding using functional and alternative reinforcers during functional communication training. Journal of Applied Behavior Analysis, 31, 543-560.

Frazier, J. R., \& Williams, B. R. (1973). The application of multiple contingencies to rocking behavior in a non-retarded child. Journal of Behavior Therapy and Experimental Psychiatry, 4, 289-291.

Hagopian, L. P, Fisher, W. W., Thibault Sullivan, M., Acquisto, J., \& LeBlanc, L. A. (1998). Effectiveness of functional communication training with and without extinction and punishment: A summary of 21 inpatient cases. Journal of Applied Behavior Analysis, 31, 211-235.

Hanley, G. P., Piazza, C. C., Fisher, W. W., Contrucci, S. A., \& Maglieri, K. A. (1997). Evaluation of client preference for function-based treatment packages. Journal of Applied Behavior Analysis, 24, 719-732.

Honig, W.K., \& Slifka, R. M. (1964). Stimulus generalization of the effects of punishment. Journal of the Experimental Analysis of Behavior, 7, 21-25.

Horner, R. H., Dunlap, G., Koegel, R. L., Carr, E. G., Sailor, W., Anderson, J, Albin, W., \& O’Neill, R. E. Toward a technology of “nonaversive” behavioral support. Journal of The Association for Persons with Severe Handicaps, 15, 125-132.

Iwata, B. A., Dorsey, M. F., Slifer, K. J., Bauman, K. E., \& Richman, G. S. (1994). Toward a functional analysis of self-injury. Journal of Applied Behavior Analysis, 27, 197-209. (Reprinted from Analysis and Intervention in Developmental Disabilities, 2, 3-20, 1982).

Iwata, B. A., Pace, G. M., Dorsey, M. F., Zarcone, J. R., Vollmer, T. R., Smith, R. G., Rodgers, T. A., Lerman, D. C., Shore, B. A., Mazaleski, J. L., Goh, H. Cowdery, G. E., Kalsher, M. J., McCosh, K. C., \& Willis, K. D. (1994). The functions of self-injurious behavior: An experimental-epidemiological analysis. Journal of Applied Behavior Analysis, 27, 215-240. 
Kennedy, C. H. (2002). Evolution of stereotypy into self-injury. In S. R. Schroeder, M.L. Oster-Granite, \& T. Thompson (Eds.). Self-Injurious Behavior. Washington, D.C.: American Psychological Association.

Kincaid, D., \& Fox, L. (2002). Person-centered planning and positive behavior support. In S. Holburn \& P. M. Vietze (Eds.). Person-Centered Planning: Research, Practice, and Future Directions. Baltimore: Brookes.

Lalli, J. S., Casey, S. D., \& Kates, K. (1995). Reducing escape behavior and increasing task completion with functional communication training, extinction, and response chaining. Journal of Applied Behavior Analysis, 28, 261-268.

Lovaas, I., Newsom, C., \& Hickman, C. (1987). Self-stimulatory behavior and perceptual reinforcement. Journal of Applied Behavior Analysis, 20, 45-68.

Matson, J. L., \& DiLorenzo, T. M. (1984). Punishment and its alternatives: A new perspective for behavior modification. New York: Springer Publishing Company.

Mayer, G. R. (1995). Preventing antisocial behavior in the school. Journal of Applied Behavior Analysis, 28, 467-478.

Mazaleski, J. L., Iwata, B. A., Rodgers, T. A., Vollmer, T. R., \& Zarcone, J. R. (1994). Protective equipment for stereotypic hand mouthing: Sensory extinction or punishment effects? Journal of Applied Behavior Analysis, 27, 345-355.

McIlvane, W. J., \& Dube, W. V. (2003). Stimulus control topography coherence theory: Foundations and extensions. The Behavior Analyst, 26, 195-213.

O’Donnell, J. (2001). The discriminative stimulus for punishment or $\mathrm{S}^{\mathrm{Dp}}$. The Behavior Analyst, 24, 261-262.

O’Donnell, J., \& Crosbie, J. (1998). Punishment generalization gradients with humans. The Psychological Record, 48, 211-232.

O’Donnell, J., Crosbie, J., Williams, D. C., \& Saunders, K. J. (2000). Stimulus control and generalization of point-loss punishment with humans. Journal of the Experimental Analysis of Behavior, 73, 261-274. 
89

Patel, M. R., Ghezzi, P. M., Rapp, J. T., O’Flaherty, C. H., \& Titterington, C. J. (2004). Manuscript accepted for publication pending revision. Establishing stimulus control over automatically reinforced echolalia in young children with autism. Research in Developmental Disabilities.

Piazza, C. C., Hanley, G. P., \& Fisher, W. W. (1996). Functional analysis and treatment of cigarette pica. Journal of Applied Behavior Analysis, 29, 437-450.

Pierce, W. D., \& Epling, W. F. (1995). Behavior Analysis and Learning. Englewood Cliffs, NJ: Prentice Hall.

Redd, W. H. \& Birnbrauer, J. S. (1969). Adults as discriminative stimuli for different reinforcement contingencies with retarded children. Journal of Experimental Child Psychology, 7, 440-447.

Rincover, A. (1978). Sensory extinction: A procedure for eliminating self-stimulatory behavior in developmentally disabled children. Journal of Abnormal Child Psychology, 6, 299-310.

Rollings, J. P., \& Baumeister, A. A. (1981). Stimulus control of stereotypic responding: Effects on target and collateral behavior. American Journal of Mental Deficiency, 86, 67-77.

Shukla, S., \& Albin, R. W. (1996). Effects of extinction alone and extinction plus functional communication training on covariation of problem behaviors. Journal of Applied Behavior Analysis, 29, 565-568.

Skinner, B. F. (1957). Verbal behavior. Prentice-Hall, Inc.: Upper Saddle River, NJ.

Stricker, J. M., Miltenberger, R. G., Anderson, C. F., Tulloch, H. E., \& Deaver, C. M. (2002). A functional analysis of finger sucking in children. Behavior Modification, 26, 424-443.

Vollmer, T. R. (1994). The concept of automatic reinforcement: Implications for behavioral research in developmental disabilities. Research in Developmental Disabilities, 15, 187-207.

Weisman, R. G. (1975). Stimulus control by response-dependent shock in discriminated punishment. Bulletin of the Psychonomic Society, 5, 427-428. 
Williams, D. C., \& Saunders, K. J. (1997). Methodological issues in the study of drug effects on cognitive skills in mental retardation. International Review of Research in Mental Retardation, 21, 147-185.

Woods, T. S. (1983). The selective suppression of a stereotypy in an autistic child: A stimulus control approach. Behavioural Psychotherapy, 11, 235-248. 